\title{
Finite element analysis of concrete-filled steel tube (CFST) columns with circular sections under eccentric load
}

\author{
Y. Ouyang ${ }^{\text {a }}$, A.K.H. Kwan ${ }^{\text {a }}$, S.H. Lo ${ }^{\text {a }}$, J.C.M. Ho ${ }^{\text {b,* }}$
}

\begin{abstract}
The casting of concrete in concrete-filled steel tube (CFST) can, via the confinement effect of the steel tube, significantly increase the ductility of the concrete and, in the case of high-strength concrete (HSC), alleviate the shortfall in ductility of the HSC. This kind of structure is gaining popularity but its behaviour is quite complicated. In an axially loaded circular CFST column, the confinement is uniform and equi-biaxial (isotropic within the cross-section). But, when the circular CFST column is under eccentric load, the confinement becomes non-uniform and anisotropic. Such complicated confinement effect is not easy to analyse and for such analysis, a rigorous finite element $(\mathrm{FE})$ method is generally needed. In this paper, a new FE model considering the lateral strain-axial strain relation of the confined concrete covering the full range from the initial elastic stage to the inelastic stage is developed for the analysis of circular CFST columns under eccentric load. The FE model is used to analyse a total of 95 CFST specimens tested by other researchers and the numerical results are compared to the published test results for verification.
\end{abstract}

Keywords: concrete-filled steel tube (CFST); confinement effect; finite element analysis

\footnotetext{
a Department of Civil Engineering, The University of Hong Kong, Hong Kong, China.

${ }^{\mathrm{b}}$ School of Civil Engineering, The University of Queensland, QLD 4072, Australia.

*Corresponding author (email: johnny.ho@uq.edu.au)
} 


\section{Introduction}

In recent years, the strength grade of concrete is becoming higher and higher. However, the ductility of concrete is generally lower at higher strength [1]. But for survivability of a concrete structure subjected to impact and earthquake, both the strength and ductility of its structural components are important. Hence, while the strength grade of concrete is pushed upwards to save weight and space, it is necessary to restore the ductility of structural components cast of the concrete to at least the original level. One good solution to this problem is to provide confinement. A conventional way of providing confinement is to put in internal steel hoops. However, this has the obvious drawback that the confinement so provided is discontinuous because of the finite spacing between successive steel hoops. In this regard, the provision of a steel tube, which is continuous, so that the structural component becomes a concrete-filled steel tube (CFST) [2-14] is generally more effective.

Like concrete confined by a fibre-reinforced polymer (FRP) jacket, the confining stress in a CFST is induced by the dilatancy of concrete under axial compression and the compatibility of lateral strains of the confining material and the confined concrete. Nonetheless, steel tube confinement and FRP confinement are not quite the same. Whilst the hoop stress in the FRP jacket keeps on increasing with the lateral strain right from the beginning until the FRP ruptures, the hoop stress in the steel tube is negligibly small at the initial elastic stage and becomes significant only after the concrete has become inelastic when its dilatancy is much larger than before. This is because the Poisson's ratio of concrete is generally smaller than that of steel at the initial elastic stage causing concrete-steel delamination at the beginning and the dilatancy of concrete gradually increases at the inelastic stage after the formation of splitting cracks. Hence, the variation of the hoop stress in the steel tube of CFST is fairly complicated.

In existing theoretical methods for predicting the structural performance of CFST, the confining stresses are sometimes assumed to be uniform and equi-biaxial (the confining stresses along the two minor principal axes in the cross-section have equal values) $[6,11,13,15,16]$. Such simplifying assumption allows easy calculations but is 
applicable only when the CFST is subjected to axial load with no eccentricity. In more general cases, where the confining stresses could be non-uniform and anisotropic, the finite element (FE) method is generally used [17-24], and commercial software, such as ANSYS or ABAQUS, which adopts the associated or non-associated plastic flow rule and Drucker-Prager failure surface in the constitutive modelling of concrete, is often employed. The plastic flow rule governs the direction of plastic strain vector, which should be normal to the flow potential surface. In this regard, the associated flow rule assumes that the flow potential surface is identical to the failure surface, whereas the non-associated flow rule assumes that the flow potential surface may be decoupled from the failure surface. The latter has more freedom in customizing the constitutive model to account for the plastic deformation characteristics of the material.

Regarding the Drucker-Prager failure surface, the friction angle $\varphi_{f}$ and cohesion $c^{\prime}$ of the material are the two parameters governing the geometry of the failure surface. The function of the Drucker-Prager failure surface is given by:

$$
F^{\prime}=\sqrt{J_{2}}-I_{1} \tan \varphi_{f}-c^{\prime}=0
$$

where $I_{1}$ is the first stress invariant and $J_{2}$ is the second deviatoric stress invariant. In ANSYS, the flow potential function has the same format as Eq. (1) except that the friction angle $\varphi_{f}$ is replaced by the dilation angle $\varphi_{d}$ [25]. If $\varphi_{d}$ is set equal to $\varphi_{f}$, the associated flow rule is applied, as shown in Fig. 1(a), whereas if $\varphi_{d}$ is different from $\varphi_{f}$, the non-associated flow rule is applied, as shown in Fig. 1(b) [26]. In ABAQUS, the flow potential function is also of the same form as Eq. (1) except that the friction angle $\varphi_{f}$ is replaced by the dilation angle $\varphi_{d}$ [27] and the extended Drucker-Prager failure surface is used so that the convexity of the failure surface can be modified.

In both ANSYS and ABAQUS, the dilatancy behaviour of concrete under triaxial stress state is governed by the dilation angle $\varphi_{d}$. Mirmiran et al. [26] tried a zero dilation angle in ANSYS when they modelled the behaviour of axially loaded FRP-confined concrete columns. It turned out that the predicted axial stress-strain curves could fit quite well with the experimental results if proper values were chosen for the friction angle and cohesion. However, they also conceded that the numerical and experimental results showed completely different trends in the variations of the 
dilatancy and volumetric strain. This was because the choice of a zero dilation angle implies that the unconfined concrete will not experience any further volumetric dilation once its plastic limit is reached and if FRP confinement is provided, the volume of the specimen will be contracting all the way. Such implications are not reasonable and in fact do not match the observed volumetric dilation by Imran and Pantazopoulou [28].

Yu et al. $[29,30]$ noticed this problem in the commercial software and introduced a solution-dependent-field-variable (SDFV) technique into ABAQUS to the effect that the dilation angle $\varphi_{d}$ is taken as a variable whose value is determined according to the field outputs after each iteration step so as to make sure that the lateral strain-axial strain relation of the concrete will match the constitutive model proposed by Teng and Lam [31], which was derived by fitting experimental results. Somehow, they employed only one value of confining stress $f_{r}$ in the lateral strain-axial strain relation. When the two lateral principal stresses $\sigma_{1}$ and $\sigma_{2}$ are equal to each other, $f_{r}=\sigma_{1}=\sigma_{2}$. When $\sigma_{1} \neq \sigma_{2}$, an effective value of $f_{r}$ (denoted by $f_{r, e f f}$ ) is assumed, as given below:

$$
f_{r, e f f}=\frac{2\left(\sigma_{1}+0.039 f_{c}\right)\left(\sigma_{2}+0.039 f_{c}\right)}{\left(\sigma_{1}+\sigma_{2}+0.078 f_{c}\right)}-0.039 f_{c}
$$

in which $f_{c}$ is the unconfined compressive strength of concrete. With better modelling of the dilation and lateral strains of the confined concrete under triaxial compression, the SDFV technique augmenting the non-associated flow rule has enabled more accurate prediction of the dilatancy behaviour of confined concrete.

However, the authors are of the view that concrete is not entirely plastic and there are alternative methods other than those based on the plasticity theory to simulate the inelastic dilatancy behaviour of confined concrete. In this paper, a new FE model that directly incorporates the lateral strain-axial strain relation of the confined concrete is developed via the Fortran 90 computer language to simulate the confinement effect of the steel tube in CFST. In the lateral strain-axial strain relation incorporated, the gradual increase in dilatancy at the inelastic stage due to the formation of splitting cracks is fully accounted for and there is no need to use any solution dependent field variable. After analysing the lateral strains and confining stresses from the lateral strain-axial strain relation of the confined concrete and the in-plane lateral equilibrium and compatibility 
conditions of the CFST section, the axial stress-strain relation at each location within the section is obtained and the load-deflection behaviour of the eccentrically loaded CFST column is evaluated by member analysis. 


\section{Constitutive modelling}

\subsection{Modelling of confined concrete}

As in previous research recently published by the authors [32,33], the FE model simulates the constitutive behaviour of concrete under confinement using the lateral stain-axial strain relation developed by Dong et al. [34], the triaxial failure surface developed by Menétrey and Willam [35] and the axial stress-strain relation of confined concrete developed by Attard and Setunge [36]. For easy reference, a summary of the mathematical expressions in these models are given in Table 1.

According to Dong et al. [34], the in-plane lateral strains of concrete each comprises of two components, an elastic component and an inelastic component. Based on this postulation, the in-plane principal lateral strains $\varepsilon_{1}$ and $\varepsilon_{2}$ in each concrete element can be expressed as $\varepsilon_{1}=\varepsilon_{1}^{e}+\varepsilon_{1}^{p}$ and $\varepsilon_{2}=\varepsilon_{2}^{e}+\varepsilon_{2}^{p}$, in which $\varepsilon_{1}^{e}$ and $\varepsilon_{2}^{e}$ are the elastic components, and $\varepsilon_{1}^{p}$ and $\varepsilon_{2}^{p}$ are the inelastic components. With these defined, the constitutive equation of concrete at element level may be expressed as:

$$
\begin{aligned}
& \left\{\begin{array}{l}
\sigma_{1} \\
\sigma_{2} \\
\tau_{12}
\end{array}\right\}=\lambda_{c}\left[\begin{array}{ccc}
1-v_{c} & v_{c} & 0 \\
v_{c} & 1-v_{c} & 0 \\
0 & 0 & \frac{1-v_{c}}{2}
\end{array}\right]\left\{\begin{array}{c}
\varepsilon_{1}-\varepsilon_{1}^{p} \\
\varepsilon_{2}-\varepsilon_{2}^{p} \\
\gamma_{12}
\end{array}\right\}+\lambda_{c} v_{c}\left\{\begin{array}{c}
\varepsilon_{3} \\
\varepsilon_{3} \\
0
\end{array}\right\} \\
& \lambda_{c}=\frac{E_{c}}{\left(1+v_{c}\right)\left(1-2 v_{c}\right)}
\end{aligned}
$$

where $E_{c}$ and $v_{c}$ are the Young's modulus and Poisson's ratio of the concrete. The inelastic components in Eq. (3a) are dependent on the axial strain in the longitudinal direction $\varepsilon_{3}$ and the lateral confining stresses $\sigma_{1}$ and $\sigma_{2}$ [32-33,37-38]. Although in this FE model, the explicit expressions for the inelastic lateral strains given by Dong et al. [34] are used, in theory, any proven expressions for the inelastic lateral strains may be incorporated into this FE model.

Triangular three-noded T3 elements are used to discretize the concrete section as shown by the white elements in Fig. 2. The stiffness matrix equation of the concrete elements in the global coordinate system is derived as: 


$$
\mathbf{F}=\Delta\left\{\mathbf{B}^{\mathrm{T}} \mathbf{A}^{\mathrm{T}} \mathbf{C} \mathbf{A} \mathbf{B} \mathbf{u}-\mathbf{B}^{\mathrm{T}} \mathbf{A}^{\mathrm{T}} \mathbf{C} \boldsymbol{\varepsilon}_{\mathbf{1 , 2}}^{\mathbf{p}}+\mathbf{B}^{\mathrm{T}}\left(\lambda v_{c} \boldsymbol{\varepsilon}_{\mathbf{3}}\right)\right\}
$$

in which $\Delta$ is the area of the T3 element; $\mathbf{B}$ is the strain-displacement matrix of the $\mathrm{T} 3$ element; $\mathbf{A}$ is the strain transformation matrix converting the global lateral strain vector $\left\{\varepsilon_{x} \varepsilon_{y} \gamma_{x y}\right\}^{\mathrm{T}}$ to the local principal strain vector $\left\{\varepsilon_{1} \varepsilon_{2} \gamma_{12}\right\}^{\mathrm{T}} ; \mathbf{u}$ is the nodal displacement vector $\left\{u_{1} v_{1} u_{2} v_{2} u_{3} v_{3}\right\}^{\mathrm{T}}$ for the T3 element; $\mathbf{\varepsilon}_{\mathbf{1 , 2}}^{\mathbf{p}}$ is the local inelastic strain vector $\left\{\varepsilon_{1}^{p}\right.$ $\left.\varepsilon_{2}^{p} 0\right\}^{\mathrm{T}} ; \boldsymbol{\varepsilon}_{\mathbf{3}}$ is the axial strain vector $\left\{\varepsilon_{3} \varepsilon_{3} 0\right\}^{\mathrm{T}}$ in both local and global coordinate systems; and $\mathbf{C}$ is the constitutive matrix of the concrete. In the numerical analysis, the axial strain $\varepsilon_{3}$ is taken as that at the centroid of the T3 element.

The triaxial failure surface developed by Menétrey and Willam [35] is given by the following mathematical expression:

$$
F(\xi, \rho, \theta)=\left(\sqrt{1.5} \frac{\rho}{f_{c}}\right)^{2}+m\left[\frac{\rho}{\sqrt{6} f_{c}} r(\theta, e)+\frac{\xi}{\sqrt{3} f_{c}}\right]-c=0
$$

where $\xi$ is the hydrostatic length; $\rho$ is deviatoric length; $\theta$ is the Lode angle; $m$ is the friction parameter; $e$ is the out-of-roundness parameter; and $c$ is the cohesion parameter. The uniaxial tensile strength $f_{t}$ is assumed as $-0.1 f_{c}$. When Eq. (5) is only describing the failure surface, $c$ should be equal to 1 . The value of $e$ can be derived by putting $\sigma_{1}=0$ and $\sigma_{2}=\sigma_{2}=1.5 \cdot f_{c}^{0.925}$ in Eq. (5):

$$
e=\frac{44.55 \cdot f_{c}^{-0.075}+6.75 \cdot f_{c}^{-0.15}-3}{89.1 \cdot f_{c}^{-0.075}-6.75 \cdot f_{c}^{-0.15}+3}
$$

as per Papanikolaou and Kappos's [39] suggestion that the biaxial-to-uniaxial compressive strength ratio of concrete should be given by $1.5 \cdot f_{c}^{-0.075}$. As far as the failure surface is concerned, $\sigma_{3}$ in Eq. (5) is equivalent to $f_{c c}$ and can be calculated from the lateral confining stresses $\sigma_{1}$ and $\sigma_{2}$ at each iteration step.

The relation between the axial strain $\varepsilon_{3}$ and the axial stress $\sigma_{3}$ of each concrete element within the cross-section may be determined by Attard and Setunge's model [36]. The mathematical expression of this model is given by: 


$$
\frac{\sigma_{3}}{f_{c c}}=\frac{a_{1}\left(\frac{\varepsilon_{3}}{\varepsilon_{c c}}\right)+a_{2}\left(\frac{\varepsilon_{3}}{\varepsilon_{c c}}\right)^{2}}{1+a_{3}\left(\frac{\varepsilon_{3}}{\varepsilon_{c c}}\right)+a_{4}\left(\frac{\varepsilon_{3}}{\varepsilon_{c c}}\right)^{2}}
$$

where $\varepsilon_{c c}$ is axial strain at peak stress corresponding to the confined concrete strength, and $a_{1}, a_{2}, a_{3}$ and $a_{4}$ are coefficients governing the shape of the stress-strain curve. The detailed mathematical formulations of Attard and Setunge's model can be found in Table 1. It should be stressed that Attard and Setunge's original mathematical expressions for the confined concrete strength $f_{c c}$ [36] is only applicable to the cases in which the confining stresses along the two principal axes have the same magnitude, i.e. $\sigma_{1}=\sigma_{2}=f_{r}$, and is replaced by Menétrey and Willam's triaxial failure surface [35] since the latter is more suitable for anisotropic cases. $f_{r}$ is also used to determine other parameters in Attard and Setunge's model. When $\sigma_{1}$ and $\sigma_{2}$ are not equal to each other, an equivalent value of $f_{r}$ should be adopted. Therefore, the assumption of $f_{r}=\min \left\{\sigma_{1}, \sigma_{2}\right\}$ that has been verified in the two previous studies by the authors [32-33] is again applied and tested herein.

The lateral strain-axial strain relation, triaxial failure surface and longitudinal axial stress-strain model are integrated together as shown in Fig. 3. At each loading step, the axial strain in each concrete element is first determined by member analysis of the CFST column. Then, from the lateral strain-axial strain relation, the inelastic lateral strains are determined using the previously obtained lateral confining stresses. With the inelastic lateral strains in each concrete element determined, the elastic lateral strains and lateral confining stresses are evaluated by a 2-D FE analysis of the cross-section taking into account the lateral equilibrium and compatibility between the confined concrete and the steel tube. Having evaluated the lateral confining stresses, the inelastic lateral strains are updated using the newly evaluated lateral confining stresses and the procedure is repeated until convergent values of lateral confining stresses are obtained. Then, from the lateral confining stresses, the triaxial failure surface is employed to evaluate the ultimate axial strength, i.e. the peak axial stress, of the confined concrete. Having evaluated the peak axial stress, the longitudinal axial stress-strain curve of the confined concrete is updated for determination of the axial stress in the concrete element. 
2.2 Modelling of steel tube

Firstly, the von-Mises yield criterion is adopted for the steel, as given below:

$$
F_{S}=\sqrt{\frac{1}{2}\left[\left(\sigma_{x}-\sigma_{y}\right)^{2}+\left(\sigma_{y}-\sigma_{z}\right)^{2}+\left(\sigma_{z}-\sigma_{x}\right)^{2}+6\left(\tau_{x y}^{2}+\tau_{y z}^{2}+\tau_{z x}^{2}\right)\right]}-\sigma_{v}=0
$$

where $\sigma_{v}$ is the von-Mises stress, $\sigma_{z}=\sigma_{3}, \varepsilon_{z}=\varepsilon_{3}$ and $\varepsilon_{z}^{p}=\varepsilon_{3}^{p}$. It is assumed that the steel is linearly elastic and perfectly plastic without strain hardening. Hence, $\sigma_{v}$ is taken simply as $f_{y}$. For an eccentrically loaded circular CFST column, the 2D FE analysis is conducted on the critical section, i.e. the mid-height section, where the out-of-plane shear stresses $\tau_{y z}$ and $\tau_{z x}$ are taken as zero due to symmetry.

Secondly, the associated flow rule is applied to calculate the plastic strains in the steel, i.e. $\varepsilon_{x}^{p}, \varepsilon_{y}^{p}, \varepsilon_{3}^{p}\left(=\varepsilon_{z}^{p}\right)$ and $\gamma_{x y}^{p}$. The constitutive equation of the steel at element level is therefore given by:

$$
\begin{aligned}
& \left\{\begin{array}{l}
\sigma_{x} \\
\sigma_{y} \\
\tau_{x y}
\end{array}\right\}=\lambda_{s}\left[\begin{array}{ccc}
1-v_{s} & v_{s} & 0 \\
v_{s} & 1-v_{s} & 0 \\
0 & 0 & \frac{1-v_{s}}{2}
\end{array}\right]\left\{\begin{array}{c}
\varepsilon_{x}-\varepsilon_{x}^{p} \\
\varepsilon_{y}-\varepsilon_{y}^{p} \\
\gamma_{x y}-\gamma_{x y}^{p}
\end{array}\right\}+\lambda_{s} v_{s}\left\{\begin{array}{c}
\varepsilon_{3}-\varepsilon_{3}^{p} \\
\varepsilon_{3}-\varepsilon_{3}^{p} \\
0
\end{array}\right\} \\
& \lambda_{s}=\frac{E_{s}}{\left(1+v_{s}\right)\left(1-2 v_{s}\right)}
\end{aligned}
$$

where $E_{s}$ and $v_{s}$ are the Young's modulus and Poisson's ratio of the steel. Triangular three-noded T3 elements are employed for the steel tube as shown by the grey elements in Fig. 2. The stiffness matrix equation of the steel elements in the global $x$-y coordinate system is derived as:

$$
\mathbf{F}^{\prime}=\Delta\left\{\mathbf{B}^{\mathrm{T}} \mathbf{C}^{\prime} \mathbf{B} \mathbf{u}-\mathbf{B}^{\mathrm{T}} \mathbf{C}^{\prime} \boldsymbol{\varepsilon}^{\mathbf{p}}+\lambda_{s} v_{s} \mathbf{B}^{\mathrm{T}}\left(\boldsymbol{\varepsilon}_{\mathbf{3}}-\boldsymbol{\varepsilon}_{\mathbf{3}}^{\mathbf{p}}\right)\right\}
$$

where $\boldsymbol{\varepsilon}^{\mathbf{p}}$ is the in-plane plastic strain vector $\left\{\begin{array}{lll}\varepsilon_{x}^{p} & \varepsilon_{y}^{p} & \gamma_{x y}^{p}\end{array}\right\}^{\mathrm{T}}, \quad \boldsymbol{\varepsilon}_{\mathbf{3}}^{\mathbf{p}}$ is the axial plastic strain vector $\left\{\begin{array}{ccc}\varepsilon_{3}^{p} & \varepsilon_{3}^{p} & 0\end{array}\right\}^{\mathrm{T}}$, and $\mathbf{C}^{\prime}$ is the constitutive matrix of the steel.

2.3 Modelling of concrete-steel interface

In order to simulate the interaction mechanism between the concrete core and 
the steel tube, concrete-steel interface elements are inserted between them, as shown in Fig. 2(b). The constitutive equation of the interface element is given by:

$$
\left\{\begin{array}{l}
Q_{1} \\
R_{1} \\
Q_{2} \\
R_{2}
\end{array}\right\}=\left[\begin{array}{cc}
-C & S \\
-S & -S \\
C & -S \\
S & C
\end{array}\right]\left[\begin{array}{cc}
k_{h} & 0 \\
0 & k_{v}
\end{array}\right]\left[\begin{array}{cccc}
-C & -S & C & S \\
S & -S & -S & C
\end{array}\right]\left\{\begin{array}{l}
u_{1} \\
v_{1} \\
u_{2} \\
v_{2}
\end{array}\right\}
$$

where $k_{h}$ is the shear stiffness along the interface; $k_{v}$ is the normal stiffness in the direction normal to the interface; $C$ and $S$ stand for $\cos \theta_{i}$ and $\sin \theta_{i}$ respectively, $\theta_{i}$ is the orientation angle of the interface element in the global $x-y$ coordinate system, $\left\{u_{1} v_{1} u_{2}\right.$ $\left.v_{2}\right\}^{\mathrm{T}}$ is the nodal displacement vector, and $\left\{Q_{1} R_{1} Q_{2} R_{2}\right\}^{\mathrm{T}}$ is the nodal force vector. $k_{h}$ and $k_{v}$ are expressed as:

$$
\left[\begin{array}{l}
k_{h} \\
k_{v}
\end{array}\right]=\frac{b_{i}}{L_{i}}\left[\begin{array}{l}
E_{h} \\
E_{v}
\end{array}\right]
$$

where $b_{i}$ is the nominal width of the interface element as half the arc length from the last to the next interface element; $L_{i}$ is the length of a hypothetical finite gap between the two material, assumed as $0.1 \mathrm{~mm} ; E_{h}$ and $E_{v}$ are the nominal elastic moduli of the interface element, both having the initial value of $100 E_{s}$ to represent that the concrete and steel are in "hard contact" and "perfect bond" at the start.

Unlike other forms of composite structures with connectors provided at the concrete-steel interfaces, CFST columns seldom have connectors provided to bond the concrete and steel tube together. Hence, delamination could occur at the concrete-steel interfaces. When the normal strain is tensile, delamination occurs and then the normal stress, normal stiffness, shear stress and shear stiffness are set equal to zero. Hence, after delamination, bond-slip can occur. Numerically, this is achieved by subtracting a residual vector term comprising equal amount of elastic nodal forces to those in the interface elements from the global force vector, i.e. the dot product of the global stiffness matrix and the displacement vector at the same iteration step. The process is repeated until the numerical results are convergent. On the other hand, when the normal strain is compressive, hard contact occurs and then the normal stiffness is restored to its initial hard contact value. At the meantime, the friction is assumed to be large enough to effect perfect bond. 


\section{FE analysis of eccentrically loaded circular CFST columns}

As shown in Fig. 3, the role of FE analysis in the model is to calculate the field of confining stresses. The axial stress of each concrete or steel T3 element in Fig. 2 is normal to the plane of the element ( $x-y$ plane). It should be noted that based on the authors' previous research [32], with high mesh density adopted, numerical result on T3 elements are not so different from those on T6. The eccentricity is defined along the $x$-axis, and the rotation of the section is therefore about $y$-axis. Because the eccentrically loaded CFST section is symmetric about the $x$-axis, only one half of the section needs to be meshed for the simulation, and the nodes on the $x$-axis do not have displacements along the $y$-axis as the boundary condition. By doing so, the time consumption will be significantly reduced without compromising the accuracy of the FE analysis. The time reduction is also dependent on the meshing technique or more specifically the bandwidth of the stiffness matrix.

The axial strain $\varepsilon_{e}$ at $x=d_{e}$ of the mid-span section is used as the primary input in terms of evenly spaced small steps to drive the analysis process. The section of an eccentrically loaded circular CFST column is subjected to axial load and bending moment at the same time, and based on the assumption that "plane sections remain plane after loading" [40-42], the axial strain $\varepsilon_{3}$ any point $(x, y)$ in the section can be determined by the axial strain $\varepsilon_{e}$ at $x=d_{e}$ and the curvature $\omega_{m}$ about the $y$-axis over the mid-span section, as shown by the following equation:

$$
\varepsilon_{3}=\varepsilon_{e}+\omega_{m}\left(x-d_{e}\right)
$$

The value of $\omega_{m}$ needs to be calculated through iterations, with its initial trial set to be $\omega_{m}=0$.

With $\varepsilon_{3}$ of each concrete and steel element being calculated through Eq. (13), the inelastic lateral strain vector $\varepsilon_{\mathbf{1 , 2}}^{\mathbf{p}}$ of concrete in Eq. (4) can be determined by Dong et al.'s [34] lateral strain-axial strain relation, and the plastic strain vectors $\boldsymbol{\varepsilon}^{\mathbf{p}}$ and $\boldsymbol{\varepsilon}_{\mathbf{3}}^{\mathbf{p}}$ of steel in Eq. (10) can be determined by von-Mises yield criterion and the associated plastic flow. Subsequently, by assembling the constitutive equations for each concrete 
element, steel element and interface element, the global stiffness matrix equation can be obtained as follows:

$$
K \cdot u=F_{p}\left\{\varepsilon_{1,2}^{p}\left[\sigma(u), \varepsilon_{3}\right], \varepsilon^{p}\right\}-F_{3}\left(\varepsilon_{3}, \varepsilon_{3}^{p}\right)
$$

where $\mathbf{F}_{\mathbf{p}}$ and $\mathbf{F}_{\mathbf{3}}$ are load vectors related to the residual strains (inelastic lateral strains of concrete and plastic strains of steel) and axial strains in the concrete elements and steel elements. It is found that Eq. (14) is a nonlinear matrix system because the residual strain vectors on the right hand side are also dependent on the nodal displacement vector on the left hand side. Hence an iteration process is adopted to calculate the approximate solutions to Eq. (14) in each loading step of the FE analysis. For example, a nodal displacement vector $\mathbf{u}_{i}$ can be calculated using the current values of axial strains and confining stresses in Step $i$ :

$$
\mathbf{K} \cdot \mathbf{u}_{i}=\mathbf{F}_{\mathbf{p}}\left\{\boldsymbol{\varepsilon}_{\mathbf{1}, \mathbf{2}}^{\mathbf{p}}\left[\sigma_{i}, \boldsymbol{\varepsilon}_{\mathbf{3}}\right], \boldsymbol{\varepsilon}^{\mathbf{p}}\right\}-\mathbf{F}_{\mathbf{3}}\left(\boldsymbol{\varepsilon}_{\mathbf{3}}, \boldsymbol{\varepsilon}_{\mathbf{3}}^{\mathbf{p}}\right)
$$

The global stiffness matrix equation is solved for $\mathbf{u}_{i}$ using $\mathbf{L D U}$ decomposition (or Cholesky decomposition) and band-solver. Then the new nodal displacement vector can be used to produce a new stress vector $\boldsymbol{\sigma}_{i}{ }^{\prime}$, which is used to compute the confining stresses for the $i+1^{\text {th }}$ iteration:

$$
\boldsymbol{\sigma}_{i+1}=r \cdot \boldsymbol{\sigma}_{i}+(1-r) \cdot \boldsymbol{\sigma}_{i}^{\prime}\left(\mathbf{u}_{i}\right),(0<r<1)
$$

where $r$ is the relaxation factor. Normally the value of $r$ is set between 0.3 and 0.7 to maintain the convergence rate during the iteration process.

After the principal lateral stresses $\sigma_{1}$ and $\sigma_{2}$ of each concrete element are converging to steady values, i.e. their approximate solutions are found, they can be used to evaluate $f_{c c}$ via Menétrey and Willam's [34] triaxial failure surface. With the input of $\varepsilon_{3}, f_{c c}, f_{r}=\min \left\{\sigma_{1}, \sigma_{2}\right\}$, and the use of Attard and Setunge [35] axial stress-strain relation, the axial stress $\sigma_{3}$ of each concrete element can be evaluated. Meanwhile, the axial stress $\sigma_{3}$ of each steel element is determined also by von-Mises yield criterion and the associated plastic flow. The eccentric load $P$ can be calculated by integrating $\sigma_{3}$ over the whole CFST section and the internal moments $M_{\text {in }}$ about $y$-axis can be calculated by integrating $\sigma_{3} x$. The moment equilibrium incorporating the secondary moment effect must be fulfilled, which is given by: 


$$
P\left(\delta_{m}+d_{e}\right)+M_{\text {in }}=0
$$

where $\delta_{m}$ is the mid-span deflection of the column, which should be updated through a second-order member analysis at the end of each iteration. The iterations about $\delta_{m}$ are denoted by $j$. When $j=1$, the deflections along the column, including $\delta_{m}$, are set to be 0 .

Within the $j^{\text {th }}$ iteration about $\delta_{m}$, if the moment equilibrium of Eq. (16) is not reached, the curvature $\omega_{m}$ about the $y$-axis over the mid-span section should be adjusted using the secant method, until the remainder moment $(R E)$ is small enough to be neglected:

$$
\omega_{m, k+2}=\omega_{m, k+1}-\frac{\left(\omega_{m, k+1}-\omega_{m, k}\right) \cdot R E_{k+1}}{R E_{k+1}-R E_{k}}
$$

It should be noted that the iterations about $\omega_{m}$ are denoted by $k$.

After the moment equilibrium of Eq. (16) is reached temporarily, the member deflection curve of the $j+1^{\text {th }}$ iteration should be updated for the calculation of secondary moment. The deflection curve can be derived from the boundary conditions that the deflection $\delta_{o}=0$ at $x=0 \mathrm{~mm}$ and the mid-span slope $\dot{\delta}_{m}$, as given by:

$$
\delta_{j+1}(x)=\iint_{0}^{x}\left(\frac{M_{e x}}{E I}\right)_{j} d x^{2}-x \int_{0}^{L / 2}\left(\frac{M_{e x}}{E I}\right) d x
$$

$\delta_{m}$ is equal to the result of Eq. (18) at $x=L / 2$. Numerical integration is performed, and the values of eternal moment $M_{e x}$ at the integration point can be evaluated by:

$$
M_{e x, j}(x)=P_{j}\left[\delta_{j}(x)+d_{e}\right]
$$

The value of flexural stiffness $E I$ is taken as $-M_{i n, J} J \omega_{m}$ right after Eq. (16) is fulfilled. The process of updating the deflection curve of the column due to secondary moment will finally stop when the variation of deflection between two consecutive iterations is very small.

Overall, there are two levels of analyses in the program, as shown in Fig. 4. The external level is about the member analysis, where $\delta_{m}$ and $\omega_{m}$ are calculated through iterations. The internal level is for the section analysis with the proposed 2D FE model incorporating the solution-dependent residual strain vectors $\varepsilon_{\mathbf{1 , 2}}^{\mathbf{p}}, \mathbf{\varepsilon}^{\mathbf{p}}$ and $\boldsymbol{\varepsilon}_{\mathbf{3}}^{\mathbf{p}}$ to obtain convergent values of confining stresses. After all, the program advances with the gradually increasing axial strain $\varepsilon_{e}$ at $x=d_{e}$ of the mid-span section. 


\section{Analysis results of CFST specimens}

To validate the new FE model, it is applied to analyse a total of 95 eccentrically loaded circular CFST specimens tested by previous researchers [44-50]. The structural parameters and material properties of these specimens are listed in Table 2. It should be noted that the values of $f_{c}$ given therein are the cylinder strengths of the concrete. As per Section 3.1 of Eurocode 2 Part 1-1 [51], the UK National Annex of Eurocode 2 [52] and Eurocode 4 [53], the true uniaxial compressive strength of the concrete is taken as 0.85 times the cylinder strength in the FE analysis.

Before starting the FE analyses, a convergence study is carried out to find out whether the finite element mesh is fine enough for accurate analysis by trying different mesh sizes in the analysis of the specimen ZC-16 tested by Zeghiche and Chaoui [47]. The numerical results so obtained are presented in Table 3. It is found that as the mesh size decreases, the predicted maximum load gradually converges to a constant value, but the computer time also increases dramatically. To strike a balance between accuracy and computer time, it is decided to adopt a nominal element size of $2 \mathrm{~mm}$ which requires a total of 1843 elements for the FE analysis. With such a mesh size, the predicted maximum load is only $0.8 \%$ higher than the convergent value.

The predicted maximum loads of the specimens analysed are compared to the corresponding test results in the last three columns of Table 2, where $P_{\text {test }}$ denotes the test result and $P_{F E}$ stands for the maximum load obtained by the FE analysis. From the values of $P_{F E} / P_{\text {test }}$ tabulated in the last column, it is seen that the FE result is sometimes slightly higher and sometimes slightly lower than the corresponding test result. For overall evaluation of numerical accuracy, the mean value of $P_{F E} / P_{\text {test }}$ in each group of specimens analysed is also presented in the table. It is evident from these mean values that the mean $P_{F E} / P_{\text {test }}$ ratio ranges from 0.93 to 1.10 . For all the 95 specimens analysed, the mean value of $P_{F E} / P_{\text {test }}$ is 1.02 , indicating that on average, the maximum load predicted by the FE analysis is about $2 \%$ higher than the test result.

To study whether the predicted maximum load by the FE analysis is equally 
accurate at different concrete strengths, the $P_{F E} / P_{\text {test }}$ ratio of each specimen is plotted against the concrete strength in Fig. 5. From the figure, it is obvious that the data points plotted are quite random but all lie closely to a trend line that is almost horizontal, indicating that the prediction error is independent of concrete strength and is basically caused by random experimental or numerical errors. Hence, the new FE model is applicable to normal-strength, high-strength and ultra-high-strength concrete with cylinder strength ranging from 25 to $115 \mathrm{MPa}$. Likewise, to study the variations in accuracy with the slenderness ratio $L / D$ and the eccentricity ratio $d_{e} / D$, the $P_{F E} / P_{\text {test }}$ ratio is plotted against $L / D$ and $d_{e} / D$ in Figs. 6 and 7, respectively. From these figures, it is apparent that in general the $P_{F E} / P_{\text {test }}$ ratio increases slightly with both the slenderness ratio $L / D$ and the eccentricity ratio $d_{e} / D$, albeit the maximum $P_{F E} / P_{\text {test }}$ ratio is only about 1.19, which is not too high. Nevertheless, in future research, particular attention should be paid to the failure behaviour of CSFT columns with large $L / D$ and $d_{e} / D$ ratios.

More detailed comparisons of the FE analysis results with the corresponding test results in the 7 groups of specimens analysed are presented in the following.

Neogi et al.'s [44] group of specimens comprises of 7 slender CFST columns with similar effective length and diameter. The steel tubes were all of grade S275 and classified as Class 1 as per Eurocode 3 [54]. The thickness of the steel tube varied from 5.11 to $8.81 \mathrm{~mm}$ whereas the concrete grade varied from Grade 20 to 40 . Moreover, the eccentricity has two distinct values of 38.1 and $47.6 \mathrm{~mm}$. For this group of specimens, the $P_{F E} / P_{\text {test }}$ ratios have a mean value of 0.98 and a standard deviation of 0.023 .

In Kilpatrick and Rangan's [45] group, there are two series of specimens. In the first series denoted by SC-0 to SC-7, the effective length varied from 802 to $2402 \mathrm{~mm}$ with all other parameters unchanged and the steel tubes belonging to Class 2, whereas in the second series denoted by SC-9 to SC-15, the eccentricity varied from 10 to $50 \mathrm{~mm}$ with all other parameters set constant and the steel tubes belonging to Class 3. All steel tubes were of grade S355, and all concretes were of Grade 50. For this group of specimens, the $P_{F E} / P_{\text {test }}$ ratios have a mean value of 1.05 and a standard deviation of 0.042. Experimental axial load-lateral deflection curves have been provided in Ref.[45] 
and the opportunity is taken to compare the FE results with these experimental results, as shown in Fig. 8, where the load-deflections curves of some typical specimens, SC-0, SC-7, SC-9 and SC-15, are plotted. From the figure, it is evident that the load-deflection curves by the FE analysis match the corresponding experimental curves quite well at both the pre-peak stage and the post-peak stage. In this regard, it should be noted that displacement control was exercised during the loading tests and thus stable post-peak load-deflection curves were obtained from the experiments.

In O'Shea and Bridge's [46] group, there are a total of 22 specimens with two nominal effective lengths (660 and $745 \mathrm{~mm}$ ), two diameters (165 and $190 \mathrm{~mm}$ ), and five steel tube thicknesses $(0.86,1.13,1.52,1.94$ and $2.82 \mathrm{~mm})$. The steel tubes were all Sub-class 3 sections but their grade varied from lower than S235 to S355. On the other hand, the concrete cylinder strength varied from 41.0 to $112.7 \mathrm{MPa}$. All these CFST specimens were subjected to axial loads with relatively small eccentricity of 6.5 to 20.8 $\mathrm{mm}$. For this group of specimens, the $P_{F E} / P_{\text {test }}$ ratios have a mean value of 0.93 and a standard deviation of 0.079 .

In Zeghiche and Chaoui's [47] group, there are 8 specimens with two effective lengths (2000 and $4000 \mathrm{~mm}$ ) and eccentricity varying from 8 to $32 \mathrm{~mm}$ in steps of $8 \mathrm{~mm}$. The steel tubes were Class 1 sections with nominal thickness of $5 \mathrm{~mm}$, nominal diameter of $160 \mathrm{~mm}$ and steel grade of S275; whereas the concrete was of Grade 100. For this group of specimens, the $P_{F E} / P_{\text {test }}$ ratios have a mean value of 0.96 and a standard deviation of 0.021 . Since experimental axial load-lateral deflection curves have been provided, the opportunity is taken to compare the FE results with these experimental results, as shown in Fig. 9, where the load-deflections curves of ZC-16, ZC-17, ZC-18 and ZC-19 are plotted. From the curves plotted, it is apparent that the load-deflection curves by the FE analysis match well the experimental curves only at the pre-peak stage and do not agree well with the experimental curves at the post-peak stage. In this regard, it should be noted that load control was exercised during the loading tests. Quite possibly, the specimens failed rapidly due to prescribed load applied to each specimen at the point of failure, leading to unstable control and unreliable post-peak load-deflection curves. 
Muciaccia et al. [48] conducted 2 sets of 4 tests with identical materials properties and almost identical configurations. The effective length varied from 1230 to $4670 \mathrm{~mm}$ with the eccentricity set constant at $25 \mathrm{~mm}$ and all other parameters remaining unchanged. The steel tubes were all Class 2 sections having nominal diameter of 140 $\mathrm{mm}$, nominal thickness of $4 \mathrm{~mm}$ and steel grade of S355; whereas the concrete was of Grade 60. For this group of specimens, the $P_{F E} / P_{\text {test }}$ ratios have a mean value of 1.03 and a standard deviation of 0.075 .

Portoles et al.'s [49] group comprises of 32 slender CFST columns having an effective length of either 2135 or $3135 \mathrm{~mm}$ and an eccentricity of either 20 or $50 \mathrm{~mm}$. The steel tubes were all Class 1 sections with varying thickness and diameter. The steel grade was S275, whereas the concrete strength ranged from Grade 30 to 90. Overall, the $P_{F E} / P_{\text {test }}$ ratios have a mean value of 1.10 and a standard deviation of 0.063 , indicating that for this group, the FE results are slightly higher than the test results.

Xue et al.'s [50] group comprises of 3 specimens with the steel tube thickness varying from 3 to $5 \mathrm{~mm}$. The effective length was $820 \mathrm{~mm}$ and the eccentricity was 50 $\mathrm{mm}$. The steel tubes have a fixed diameter of $219 \mathrm{~mm}$ but could be of Class 2, Class 3 or Sub-class 3. The steel was of Grade S275 whereas the concrete was of Grade 50. For these specimens, the $P_{F E} / P_{\text {test }}$ ratios have a mean value of 0.96 and a standard deviation of 0.021

\section{Conclusions}

In the analysis of a CFST member, it is important to properly simulate the lateral strain-axial strain relation of the confined concrete because the lateral strains, which do not follow any plastic flow theory, have great effects on the confining stresses induced. In this research, Dong et al.'s lateral strain-axial strain model [34], Menétrey and Willam's triaxial failure surface [35] and Attard and Setunge's axial stress-strain model under confined condition [36] are integrated together to form a new FE model for the analysis of CFST members. The new FE model has been applied to analyse a total of 95 eccentrically loaded circular CFST specimens tested by other researchers [44-50], which cover very wide ranges of concrete strength, steel strength, slenderness ratio and eccentricity ratio, and the FE results are compared to the respectively experimental results so as to evaluate the accuracy and applicability of the FE model. 
For each specimen analysed, the predicted maximum load by the FE analysis $P_{F E}$ is compared to the corresponding experimental result $P_{\text {test }}$ in the form of the $P_{F E} / P_{\text {test }}$ ratio. It has been found that for all the 95 specimens analysed, the mean value of the $P_{F E} / P_{\text {test }}$ ratio is 1.02 , indicating that on the whole, the predicted maximum loads by the FE analysis agree very well with the experimental results. Plotting the $P_{F E} / P_{\text {test }}$ ratio against the concrete strength, slenderness ratio and eccentricity ratio, it has also been found that the $P_{F E} / P_{\text {test }}$ ratio remains at around 1.02 within the whole range of concrete cylinder strength from 25 to $115 \mathrm{MPa}$, whereas the $P_{F E} / P_{\text {test }}$ ratio is slightly lower than 1.00 when the slenderness ratio and eccentricity ratio are relatively small and increases slightly as these two ratios increase. Hence, the FE model should be equally applicable to normal-strength, high-strength and ultra-high-strength concretes but may not be as accurate when the slenderness ratio and/or eccentricity ratio are relatively large.

Regarding the nonlinear load-deflection curves, it is evident that for the specimens tested under displacement control, the axial load-lateral deflections curves obtained by the FE analysis agree quite well with the experimentally curves at both the pre-peak stage and the post-peak stage, but for the specimens tested under load control, the axial load-lateral deflection curves obtained by the FE analysis agree well with the experimentally curves only at the pre-peak stage and do not always agree well at the post-peak stage. The discrepancy between the analytical and experimental axial load-lateral deflection curves at the post-peak stage does pose some concern. It is recommended that in future, all tests should be carried out under displacement control and the FE model should be refined to consider the second order effect incurred by dimensional imperfection of the steel tube.

Lastly, it should be emphasized that the newly developed FE model is an open framework. In theory, any lateral strain-axial strain model, any triaxial failure surface and any axial stress-strain model under confined condition other than those incorporated herein can be used. Hence, if there is any better model based on a more advanced theory or based on a more comprehensive set of test results, the better model may be plugged into the framework for further development and enhanced performance of the FE model. Moreover, the FE model may also be a basis for future extension to three-dimensional analysis and to cater for local buckling of the steel tube. 


\section{References}

[1] Ouyang Y, Ho JCM. Curvature-relevant analysis on eccentrically loaded circular concrete-filled steel tube columns. Magazine of Concrete Research, ICE 2014;66(24):1263-1276.

[2] Hajjar JF, Molodan A, Schiller PH. A distributed plasticity model for cyclic analysis of concrete-filled steel tube beam-columns and composite frames. Engineering Structures 1998;20(4-6):398-412.

[3] Susantha KAS, Ge HB, Usami T. Uniaxial stress-strain relationship of concrete confined by various shaped steel tubes. Engineering Structures 2001;23(10):1331-1347.

[4] Fujimoto T, Mukai A, Nishiyama I, Sakino K. Behavior of eccentrically loaded concrete-filled steel tubular columns. Journal of Structural Engineering, ASCE 2004;130(2):203-212.

[5] Cai J, He ZQ. Axial load behaviour of square CFT stub column with binding bars. Journal of Constructional Steel Research 2006;62(5):472-483.

[6] Hatzigeorgiou GD. Numerical model for the behavior and capacity of circular CFT columns, Part I: Theory. Engineering Structures 2008;30(6):1573-1578.

[7] Hatzigeorgiou GD. Numerical model for the behavior and capacity of circular CFT columns, Part II: Verification and extension. Engineering Structures 2008;30(6):1579-1589.

[8] Liang QQ. Performance-based analysis of concrete-filled steel tubular beam-columns, Part I: Theory and algorithms. Journal of Constructional Steel Research 2009;65(2):363-372.

[9] Liang QQ. Performance-based analysis of concrete-filled steel tubular beam-columns, Part II: Verification and applications. Journal of Constructional Steel Research 2009;65(2):351-362.

[10] Liang QQ, Fragomeni S. Nonlinear analysis of circular concrete-filled steel tubular short columns under axial loading. Journal of Constructional Steel Research 2009;65(12):2186-2196.

[11] Liang QQ, Fragomeni S. Nonlinear analysis of circular concrete-filled steel tubular short columns under eccentric loading. Journal of Constructional Steel Research 2010;66(2):159-169. 
[12] Zhao H, Kunnath SK, Yuan Y. Simplified nonlinear response simulation of composite steel-concrete beams and CFST columns. Engineering Structures 2010;32(9):2825-2831.

[13] Liang QQ. High strength circular concrete-filled steel tubular slender beam-columns, Part I: Numerical analysis. Journal of Constructional Steel Research 2011;67(2):164-171.

[14] Liang QQ. High strength circular concrete-filled steel tubular slender beam-columns, Part II: Fundamental behavior. Journal of Constructional Steel Research 2011;67(2):172-180.

[15] Tang J, Hino S, Kuroda I, Ohta T. Modeling of stress-strain relationships for steel and concrete in concrete filled circular steel tubular columns. Steel Construction Engineering, JSSC 1996;3(11):35-46.

[16] Lee SH, Uy B, Kim SH, Choi YH, Choi SM. Behavior of high-strength circular concrete-filled steel tubular (CFST) column under eccentric loading. Journal of Constructional Steel Research 2011;67(1):1-13.

[17] Tao Z, Wang ZB, Yu Q. Finite element modelling of concrete-filled steel stub columns under axial compression. Journal of Constructional Steel Research 2013;89:121-131.

[18] Hu HT, Schnobrich WC. Constitutive modeling of concrete by using nonassociated plasticity. Journal of Materials in Civil Engineering, ASCE 1989;1(4):199-216.

[19] Schneider SP. Axially loaded concrete-filled steel tubes. Journal of Structural Engineering, ASCE 1998;124(10):1125-1138.

[20] Hu HT, Huang CS, Wu MH, Wu WM. Nonlinear analysis of axially loaded concrete-filled tube columns with confinement effect. Journal of Structural Engineering, ASCE 2003;129(10):1322-1329.

[21] Hu HT, Huang CS, Chen ZL. Finite element analysis of CFT columns subjected to an axial compressive force and bending moment in combination. Journal of Constructional Steel Research 2005;61(12):1692-1712.

[22] Hu HT, Su FC, Elchalakani M. Finite element analysis of CFT columns subjected to pure bending moment. Steel and Composite Structures 2010;10(5):415-428.

[23] Xu T, Xiang T, Zhao R, Zhan Y. Nonlinear finite element analysis of circular concrete-filled steel tube structures. Structural Engineering and Mechanics 
2010;35(3):315-333.

[24] Yang YF, Han LH. Behaviour of concrete filled steel tubular (CFST) stub columns under eccentric partial compression. Thin-Walled Structures 2011;49(2):379-395.

[25] Swanson Analysis Systems. ANSYS Structural Nonlinearities Manual Version $5.4,1995$.

[26] Mirmiran A, Zagers K, Yuan WQ. Nolinear finite element modeling of concrete confined by fiber composites. Finite Elements in Analysis and Design 2000;35:79-96.

[27] Dassault Systèmes Simulia Corporation. ABAQUS User Manual Version 6.11, 2011.

[28] Imran I, Pantazopoulou SJ. Experimental study of plain concrete under triaxial stress. ACI Materials Journal 1996;93(6):589-601.

[29] Yu T, Teng JG, Wong YL, Dong SL. Finite element modeling of confined concrete-I: Drucker-Prager type plasticity model. Engineering Structures 2010;32(3):665-679.

[30] Yu T, Teng JG, Wong YL, Dong SL. Finite element modeling of confined concrete-II: Plastic-damage model. Engineering Structures 2010;32(3):680-691.

[31] Teng JG, Lam L. Behavior and modeling of fiber reinforced polymer-confined concrete. Journal of Structural Engineering, ASCE 2004;130(11):1713-1723.

[32] Lo SH, Kwan AKH, Ouyang Y, Ho JCM. Finite element analysis of axially loaded FRP-confined rectangular concrete columns. Engineering Structures 2015;100(1):253-263.

[33] Ouyang Y, Lo SH, Kwan AKH, Ho JCM. A new analysis method for polymer-confined concrete columns. Structures and Buildings 2016;169(12):892-911.

[34] Dong CX, Kwan AKH, Ho JCM. A constitutive model for predicting the lateral strain of confined concrete. Engineering Structures 2015;91:155-166.

[35] Menétrey P, Willam KJ. Triaxial failure criterion for concrete and its generalization. ACI Structural Journal 1995;92(3):311-318.

[36] Attard MM, Setunge S. Stress-strain relationship of confined and unconfined concrete. ACI Materials Journal 1996;93(5):432-441.

[37] Dong CX, Kwan AKH, Ho JCM. Effects of confining stiffness and rupture strain 
on performance of FRP confined concrete. Engineering Structures 2015;97:1-14.

[38] Kwan AKH, Dong CX, Ho JCM. Axial and lateral stress-strain model for FRP confined concrete. Engineering Structures 2015;99:285-295.

[39] Papanikolaou VK, Kappos AJ. Confinement-sensitive plasticity constitutive model for concrete in triaxial compression. International Journal of Solids and Structures 2007;44(21):7021-7048.

[40] Kwan KH, Liauw TC. Computerized ultimate strength analysis of reinforced concrete sections subjected to axial compression and biaxial bending. Computers and Structures 1985;21(6):1119-1127.

[41] Ho JCM, Kwan AKH, Pam HJ. Theoretical analysis of post-peak flexural behavior of normal- and high-strength concrete beams. Structural Design of Tall and Special Buildings 2003;12(2):109-125.

[42] Ho JCM, Lam JYK, Kwan AKH. Effectiveness of adding confinement for ductility improvement of high-strength concrete columns. Engineering Structures 2010;32(3):714-725.

[43] $\mathrm{Hu}$ B, Wang JG, Li GQ. Numerical simulation and strength models of FRP-wrapped reinforced concrete columns under eccentric loading. Construction and Building Materials 2011;25(5):2751-2763.

[44] Neogi PK, Sen HK, Chapman JC. Concrete-filled tubular steel columns under eccentric loading. The Structural Engineer 1969;47(5):187-195.

[45] Kilpatrick AE, Rangan BV. Tests on high-strength concrete-filled steel tubular columns. ACI Structural Journal 1999;96(2):268-274.

[46] O'Shea MD, Bridge RQ. Design of circular thin-walled concrete-filled steel tubes. Journal of Structural Engineering, ASCE 2000;126(11):1295-1303.

[47] Zeghiche J, Chaoui K. An experimental behaviour of concrete-filled steel tubular columns. Journal of Constructional Steel Research 2005;61(1):53-66.

[48] Muciaccia G, Giussani F, Rosati G, Mola F. Response of self-compacting concrete filled tubes under eccentric compression. Journal of Constructional Steel Research 2011;67(5):904-916.

[49] Portoles JM, Romero ML, Bonet JL, Filippou FC. Experimental study of high strength concrete-filled circular tubular columns under eccentric loading. Journal of Constructional Steel Research 2011;67(4):623-633.

[50] Xue JQ, Briseghella B, Chen BC. Effects of debonding on circular CFST stub 
columns. Journal of Constructional Steel Research 2012;69(1):107-114.

[51] European Committee for Standardization. EN 1992-1-1:2004+A1:2014, Eurocode 2: Design of concrete structures, Part 1-1: General rules and rules for buildings (incorporating corrigenda January 2008, November 2010 and January 2014), 2014.

[52] British Standard Institution. NA+A2:2014 to BS EN 1992-1-1:2004+A1:2014, UK National Annex to Eurocode 2: Design of concrete structures, Part 1-1: General rules and rules for buildings, 2015.

[53] European Committee for Standardization. EN 1994-1-1, Eurocode 4: Design of composite steel and concrete structures, Part 1-1: General rules and rules for buildings, 2004.

[54] European Committee for Standardization. EN 1993-1-1:2005: Eurocode 3, Design of Steel Structures, Part 1-1: General rules and rules for buildings, 2005. 


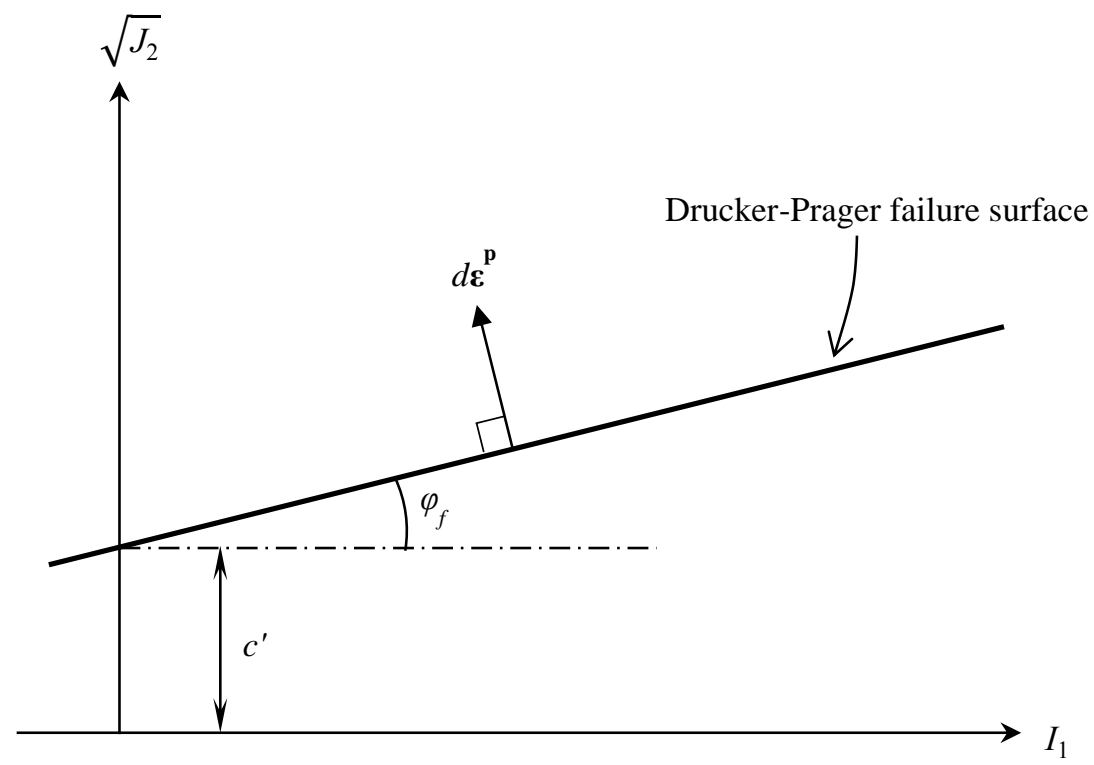

(a) Associated plastic flow

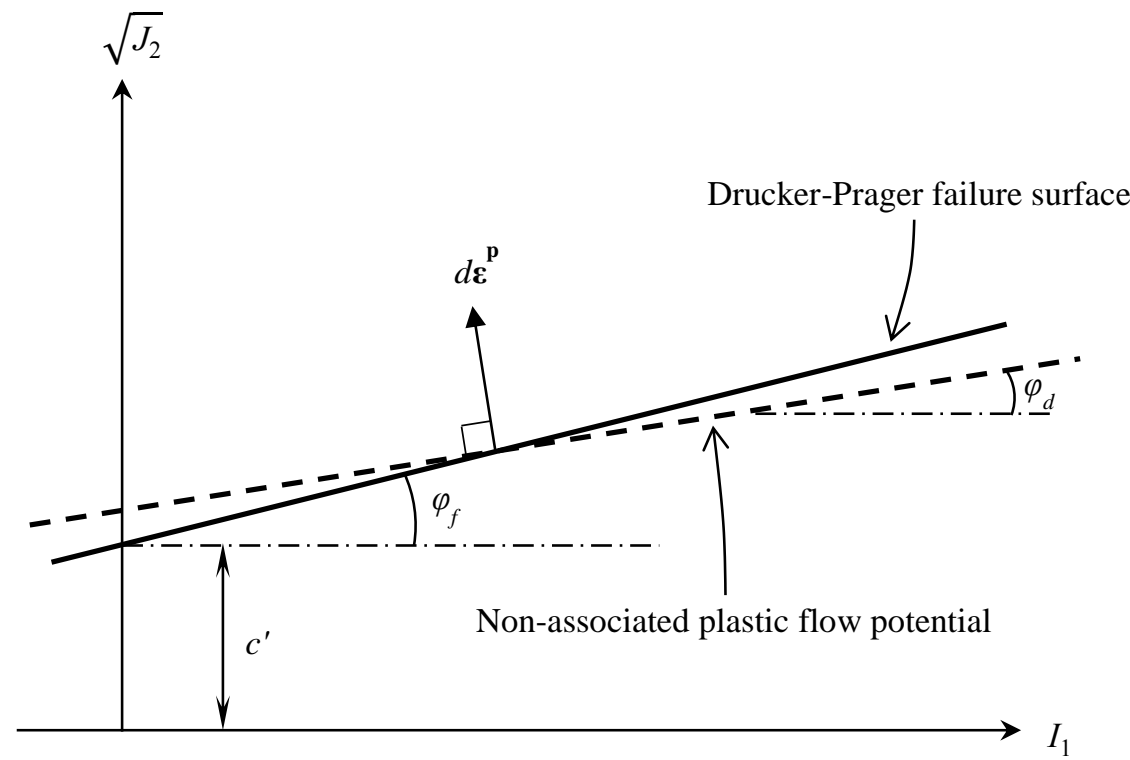

(b) Non-associated plastic flow

Figure 1. Drucker-Prager failure surface and plastic flow rules 


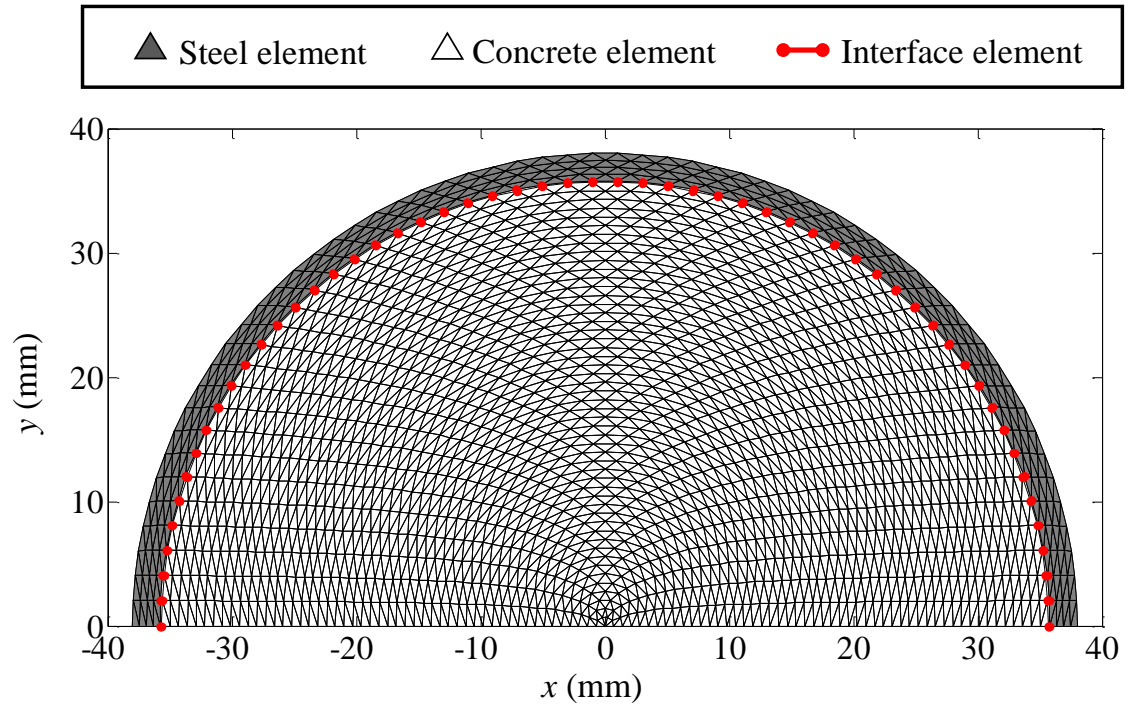

(a) Overall view

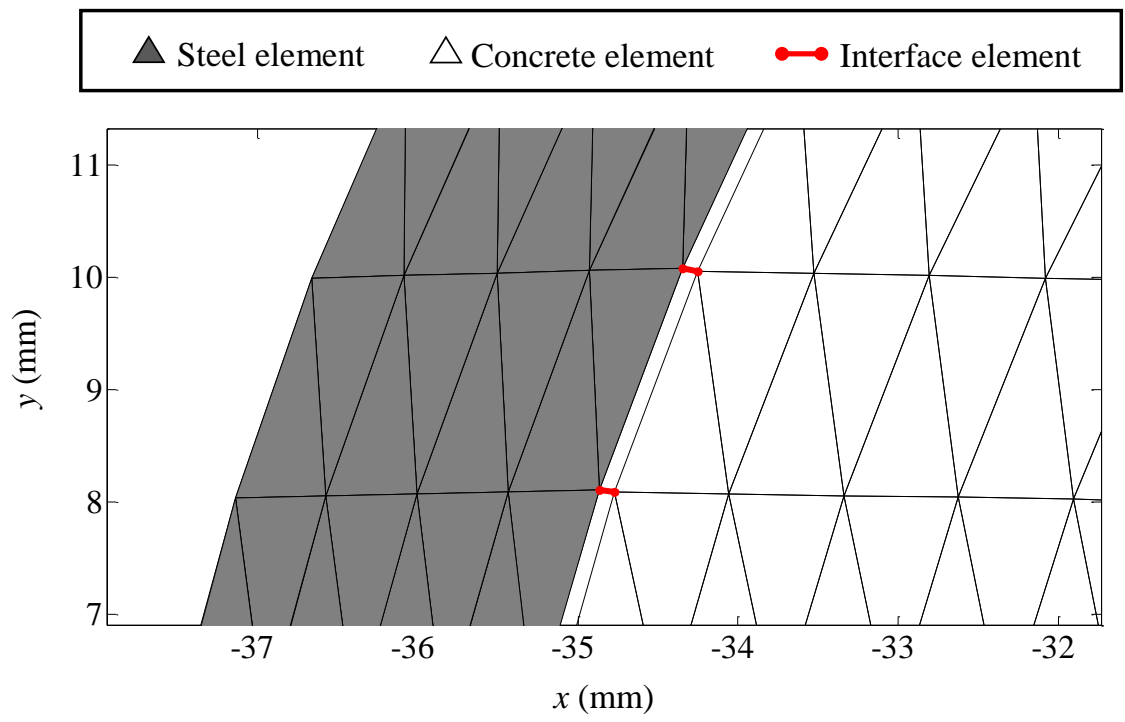

(b) Interface between steel and concrete

Figure 2. FE mesh for a CFST section 


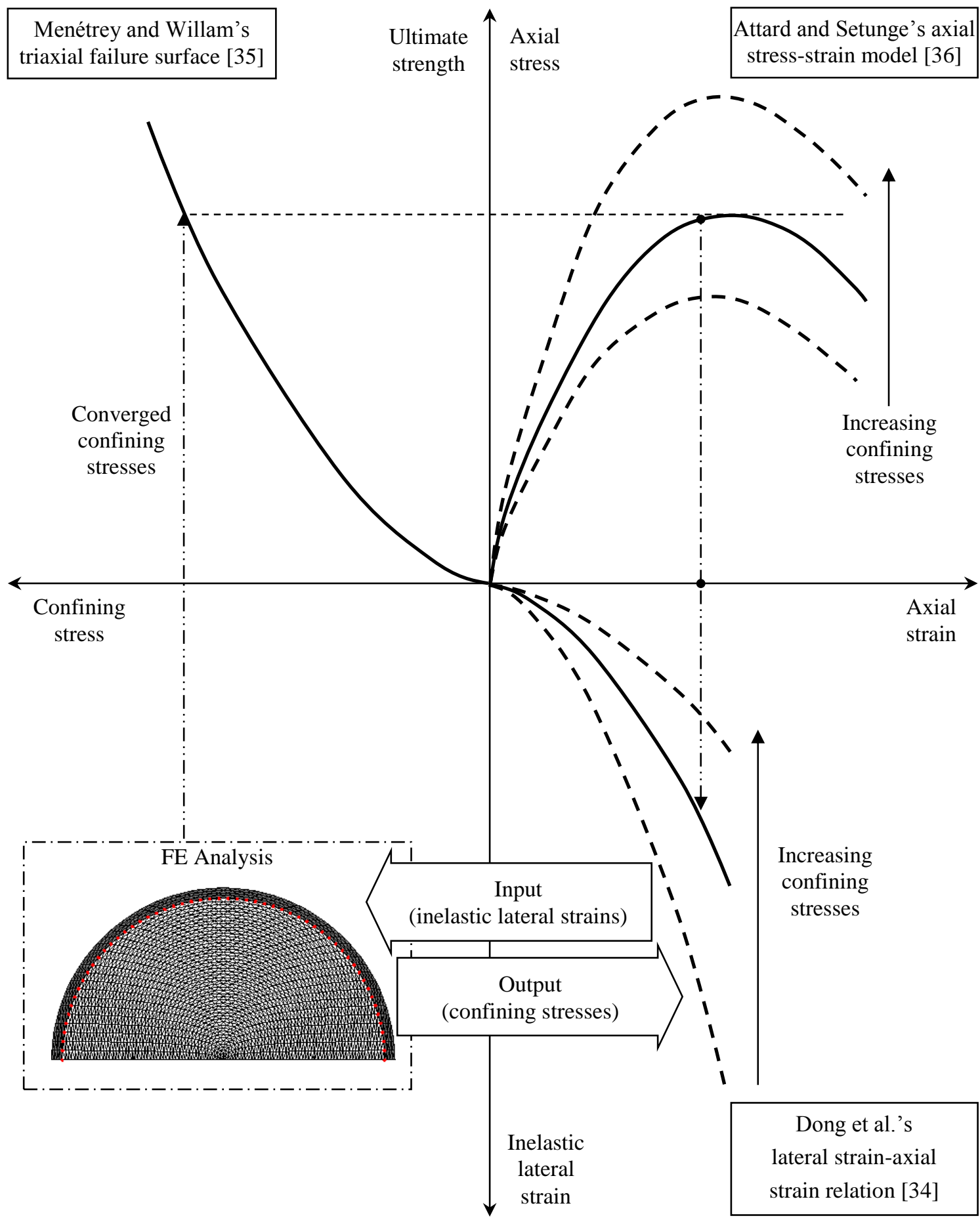

Figure 3. Integration of the three concrete models 


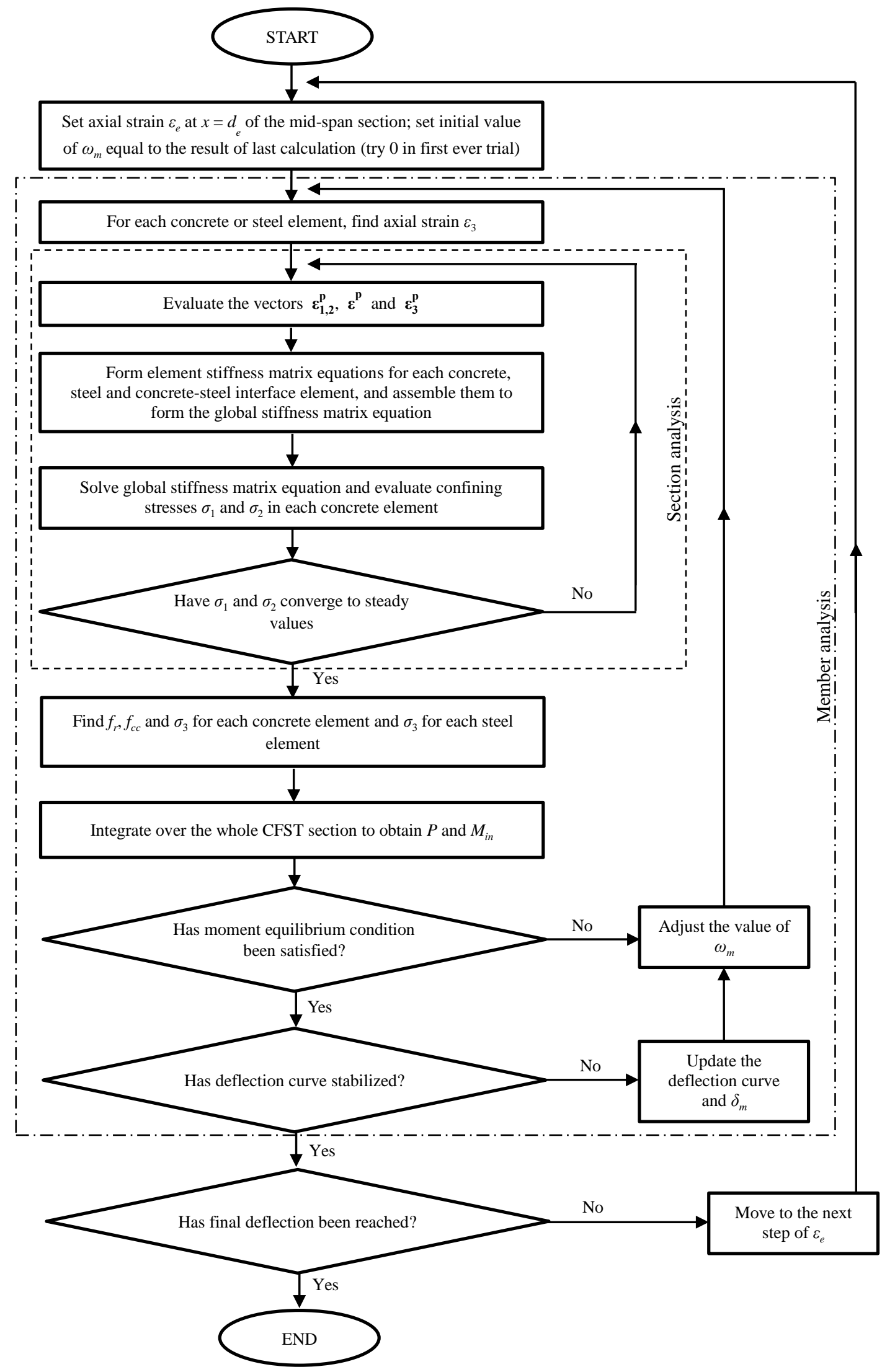

Figure 4. Procedures for the FE analysis 


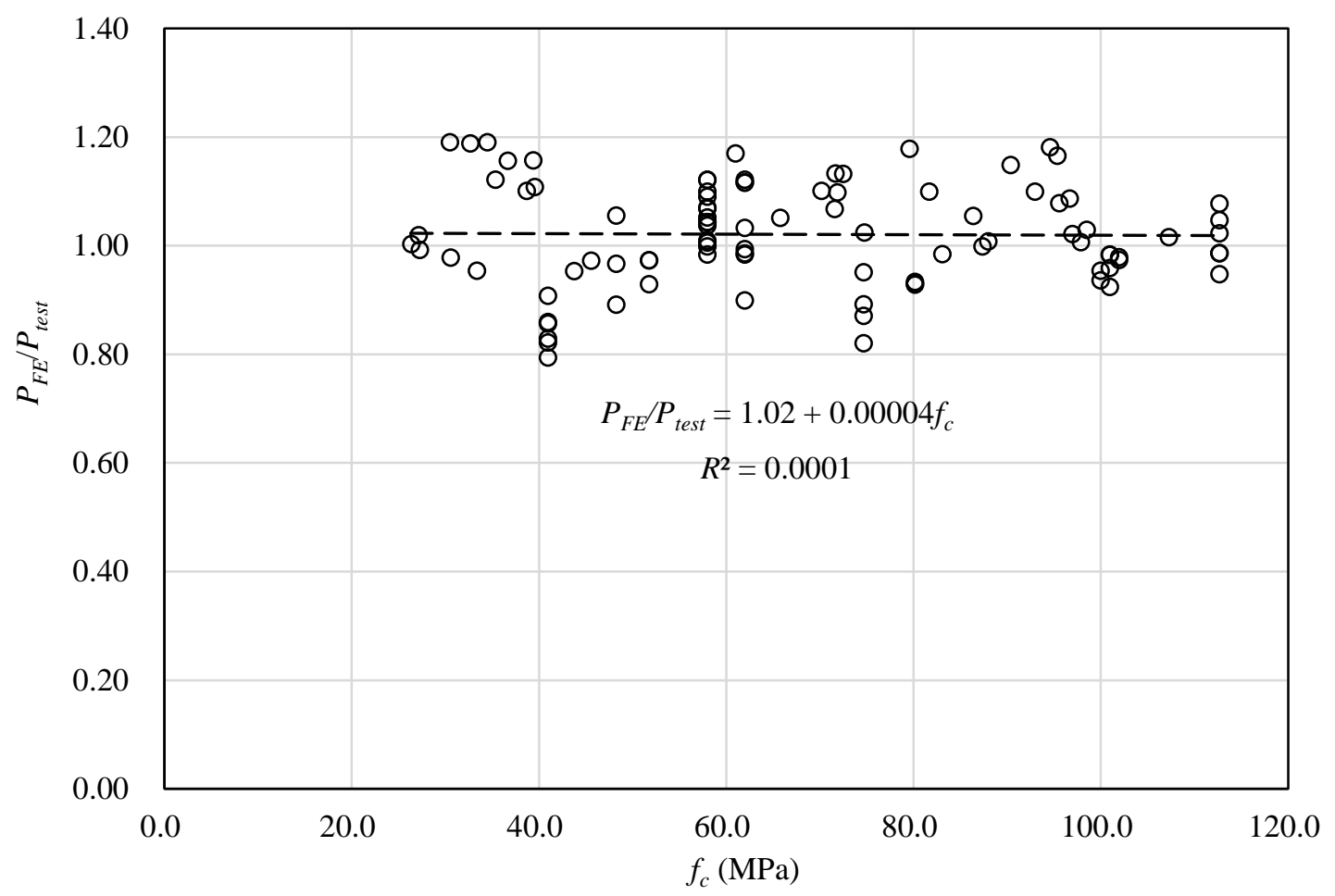

Figure 5. Variation of $P_{F E} / P_{\text {test }}$ with $f_{c}$ 


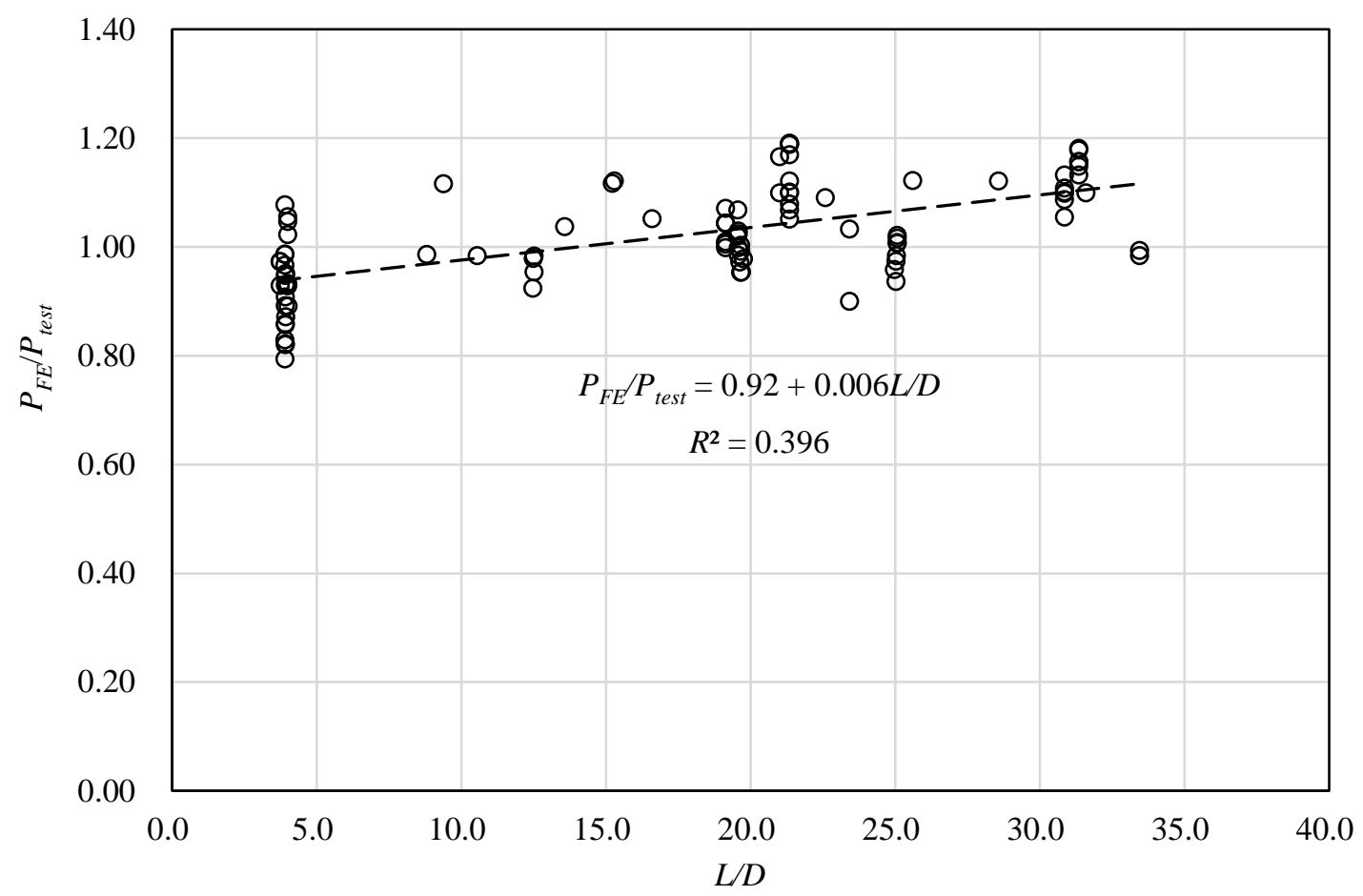

Figure 6. Variation of $P_{F E} / P_{\text {test }}$ with $L / D$ 


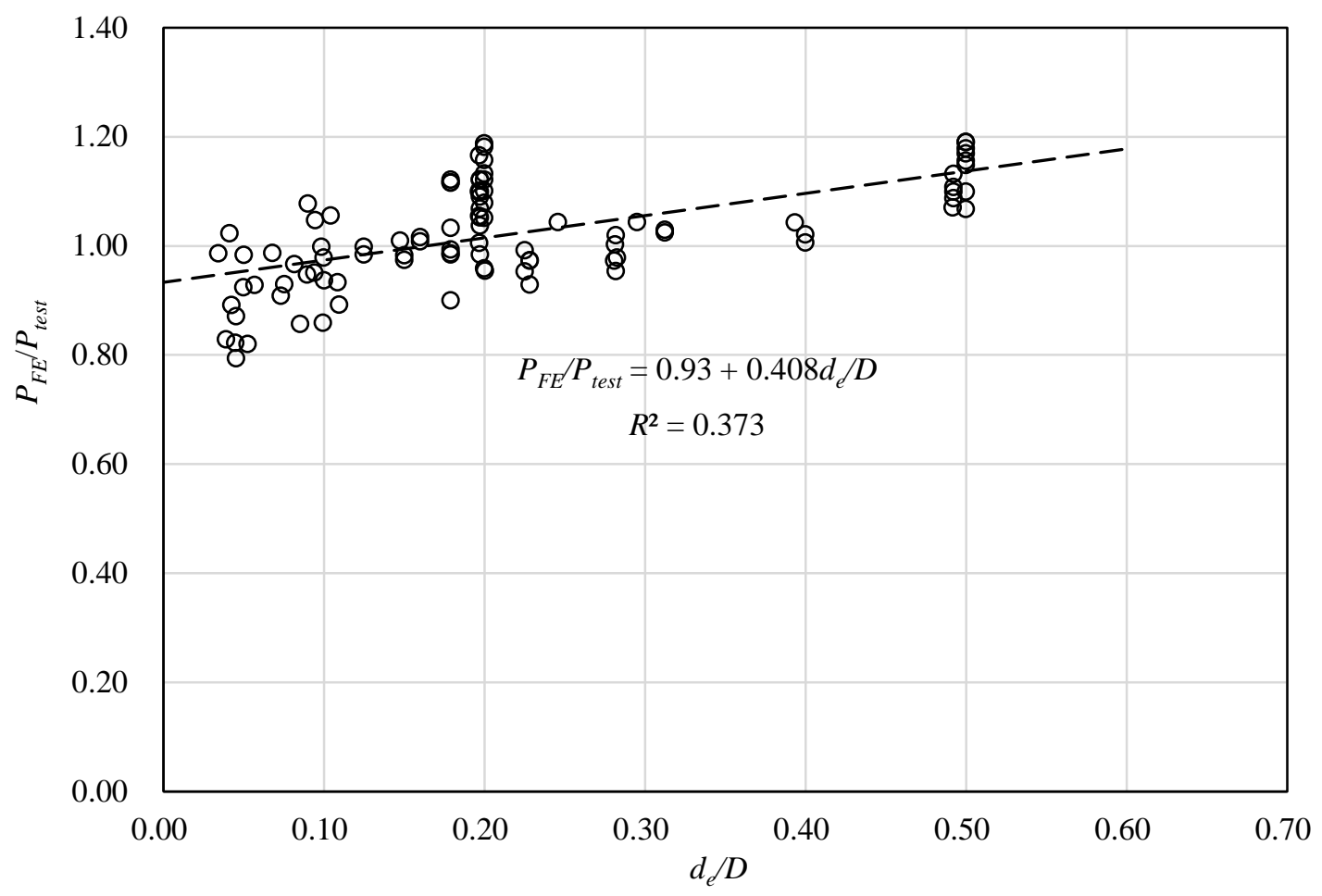

Figure 7. Variation of $P_{F E} / P_{\text {test }}$ with $d_{e} / D$ 

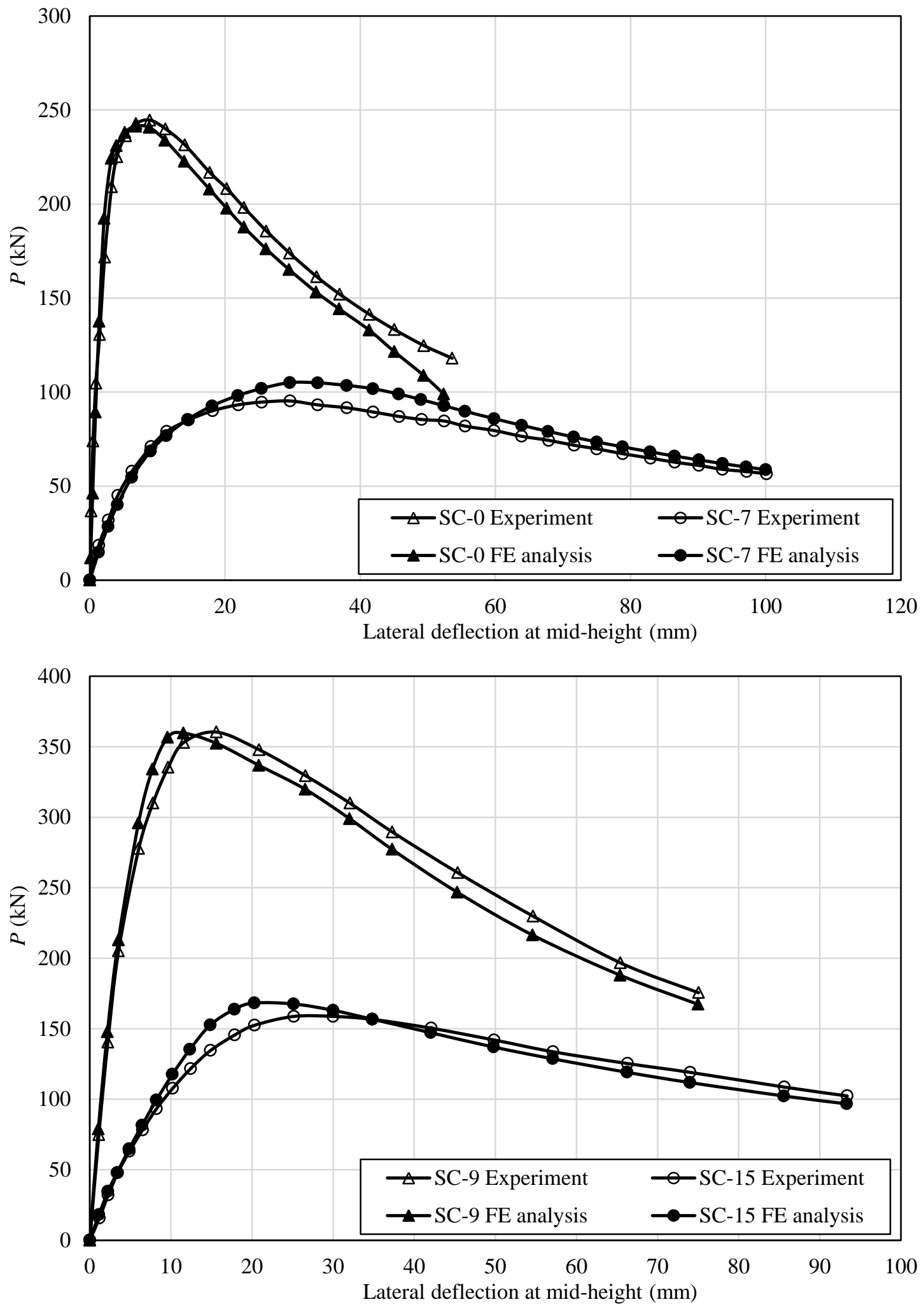

Figure 8. Eccentric load - mid-height lateral deflection curves of Kilpatrick and Rangan's specimens [45] 

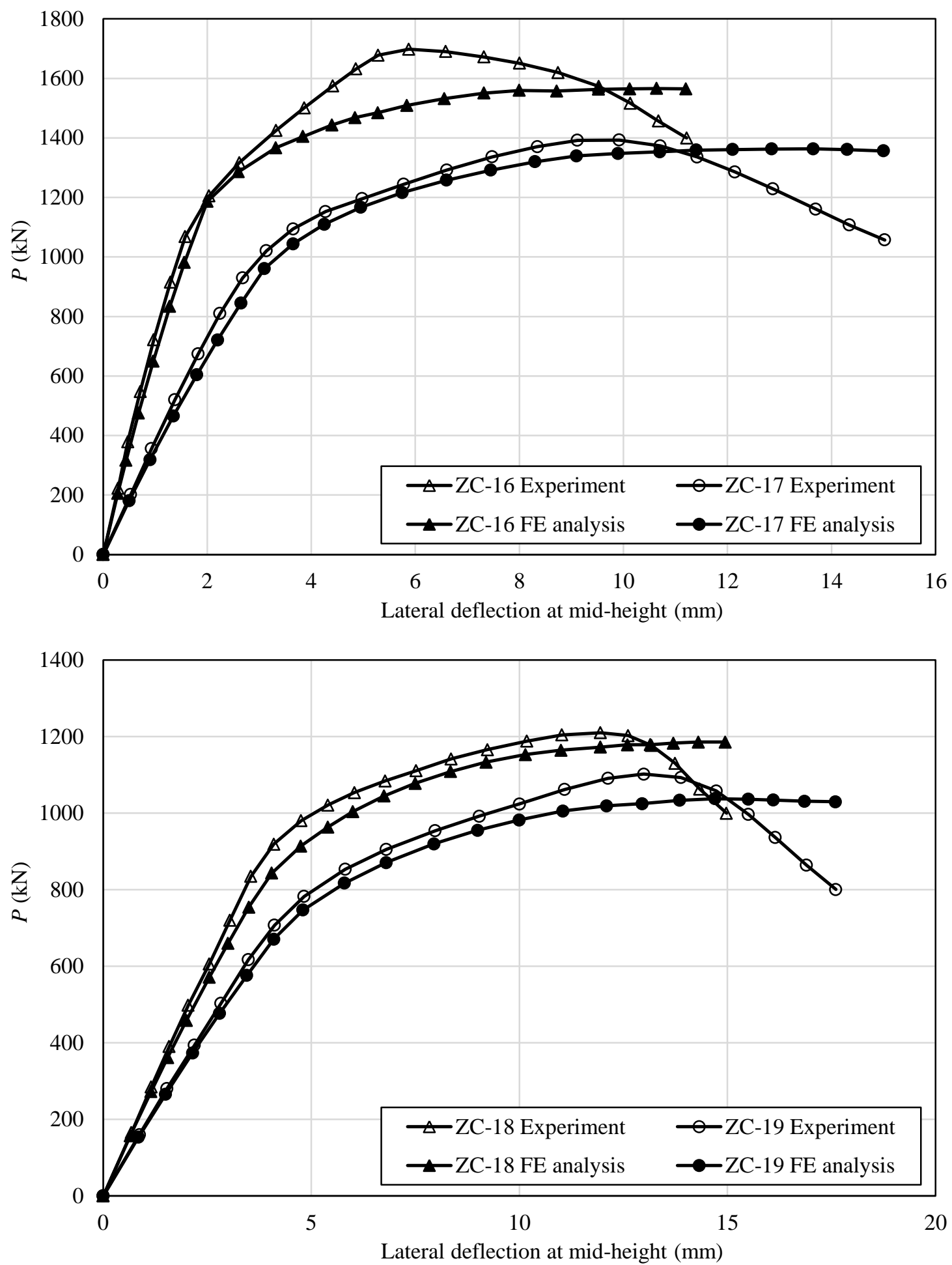

Figure 9. Eccentric load - mid-height lateral deflection curves of Zeghiche and Chaoui's specimens [47] 
Table 1. Adopted concrete models

\begin{tabular}{|c|c|c|}
\hline Authors & \multicolumn{2}{|c|}{ Model Expressions } \\
\hline Dong et al. [34] & $\begin{array}{l}\varepsilon_{1}^{p}=-19.1\left(\varepsilon_{3}-\varepsilon_{3,1}^{\lim }\right)^{1.5}\{0.1+0.9 \\
\varepsilon_{2}^{p}=-19.1\left(\varepsilon_{3}-\varepsilon_{3,2}^{\lim }\right)^{1.5}\{0.1+0.9 \\
\text { where: } \\
\varepsilon_{3,1}^{\lim }=\varepsilon_{c o}\left(0.44+0.0021 f_{c}-0.00\right. \\
\varepsilon_{3,2}^{\lim }=\varepsilon_{c o}\left(0.44+0.0021 f_{c}-0.00\right.\end{array}$ & $\begin{array}{l}\left.\left.\left.-5.3\left(\frac{\sigma_{1}}{f_{c}}\right)^{1.1}\right)\right]\right\} \\
\left.\left.\left.-5.3\left(\frac{\sigma_{2}}{f_{c}}\right)^{1.1}\right)\right]\right\} \\
{\left[1+30 \exp \left(-0.013 f_{c}\right) \frac{\sigma_{1}}{f_{c}}\right]} \\
{\left[1+30 \exp \left(-0.013 f_{c}\right) \frac{\sigma_{2}}{f_{c}}\right]}\end{array}$ \\
\hline $\begin{array}{c}\text { Menétrey and } \\
\text { Willam [35] }\end{array}$ & $\begin{array}{l}F(\xi, \rho, \theta)=\left(\sqrt{1.5} \frac{\rho}{f_{c}}\right)^{2}+m\left[\frac{\rho}{\sqrt{6} f} f_{c}\right. \\
\text { where: } \\
\xi=\frac{I_{1}}{\sqrt{3}} ; \quad I_{1}=\sigma_{1}+\sigma_{2}+\sigma_{3} \\
\rho=\sqrt{2 J_{2}} ; \quad J_{2}=\frac{1}{6}\left[\left(\sigma_{1}-\sigma_{2}\right)^{2}+\right. \\
\theta=\frac{1}{3} \cos ^{-1}\left(\frac{3 \sqrt{3} J_{3}}{2 J_{2} / 3}\right) ; \quad J_{3}=\left(\sigma_{1}-\right. \\
m=3 \frac{f_{c}^{2}-f_{t}^{2}}{f_{c} f_{t}} \cdot \frac{e}{e+1} \\
r(\theta, e)=\frac{4\left(1-e^{2}\right) \cos ^{2} \theta+}{2\left(1-e^{2}\right) \cos \theta+(2 e-1)\left[4\left(1-\frac{c}{2}\right.\right.}\end{array}$ & $\begin{array}{l}\left.+\frac{\xi}{\sqrt{3} f}\right]-c=0 \\
\left.\left.-\frac{I_{3}}{2}\right)^{2}+\left(\sigma_{3}-\sigma_{1}\right)^{2}\right] \\
\left.-\frac{I_{1}}{3}\right) \cdot\left(\sigma_{3}-\frac{I_{1}}{3}\right) \\
\frac{\left.+5 e^{2}-4 e\right]^{1 / 2}}{}\end{array}$ \\
\hline $\begin{array}{c}\text { Attard and } \\
\text { Setunge [36] }\end{array}$ & $\begin{array}{l}\frac{\sigma_{3}}{f_{c c}}=\frac{\alpha_{1}\left(\frac{\varepsilon_{3}}{\varepsilon_{c c}}\right)+\alpha_{2}\left(\frac{\varepsilon_{3}}{\varepsilon_{c c}}\right)^{2}}{1+\alpha_{3}\left(\frac{\varepsilon_{3}}{\varepsilon_{c c}}\right)+\alpha_{4}\left(\frac{\varepsilon_{3}}{\varepsilon_{c c}}\right)^{2}} \\
\frac{\varepsilon_{c c}}{\varepsilon_{c o}}=1+\left(17-0.06 f_{c}\right)\left(\frac{f_{r}}{f_{c}}\right) \\
\text { Ascending branch: } \\
\alpha_{1}=\frac{E_{t i \varepsilon_{c o}}}{f_{c}} \\
\alpha_{2}=\frac{\left(\alpha_{1}-1\right)^{2}}{\frac{E_{t i}}{E_{c}}\left(1-\frac{f_{p l}}{f_{c}}\right)}+\frac{\alpha_{1}^{2}\left(1-\frac{E_{t i}}{E_{c}}\right)}{\left(\frac{E_{t i}}{E_{c}}\right)^{2}\left[\frac{f_{p l}}{f_{c}}-\left(\frac{f_{p l}}{f_{c}}\right)^{2}\right]}-1 \\
\alpha_{3}=\alpha_{1}-2 \\
\alpha_{4}=\alpha_{2}+1\end{array}$ & $\begin{array}{l}\text { Descending branch: } \\
\alpha_{1}=\left(\frac{\varepsilon_{2 i}-\varepsilon_{i}}{\varepsilon_{c o}}\right)\left(\frac{\varepsilon_{2 i} E_{i}}{f_{c c}-f_{i}}-\frac{4 \varepsilon_{i} E_{2 i}}{f_{c c}-f_{2 i}}\right) \\
\alpha_{2}=\left(\varepsilon_{2 i}-\varepsilon_{i}\right)\left(\frac{E_{i}}{f_{c c}-f_{i}}-\frac{4 E_{2 i}}{f_{c c}-f_{2 i}}\right) \\
\alpha_{3}=\alpha_{1}-2 \\
\alpha_{4}=\alpha_{2}+1 \\
\frac{f_{i}}{f_{c c}}=\frac{\frac{f_{i c}}{f_{c}}-1}{5.06\left(\frac{f_{r}}{f_{c}}\right)^{0.57}+1}+1 \\
\frac{f_{2 i}}{f_{c c}}=\frac{\frac{f_{2 i c}}{f_{c}}-1}{6.35\left(\frac{f_{r}}{f_{c}}\right)^{0.62}+1}+1 \\
\frac{\frac{f}{i c}_{i}}{\varepsilon_{c c}}=\frac{\frac{f_{f}}{f_{c}}-2}{1.12\left(\frac{f_{r}}{f_{c}}\right)^{0.26}+1}+2 \\
\varepsilon_{2 i}=2 \varepsilon_{i}-\varepsilon_{c c} \\
\frac{f_{2 i c}}{f_{c}}=1.45-0.25 \ln \left(f_{c}\right)\end{array}$ \\
\hline
\end{tabular}


Table 2(a). Data of the eccentrically loaded circular-sectioned CFST specimens (Part I).

\begin{tabular}{|c|c|c|c|c|c|c|c|c|c|c|c|}
\hline Ref. & Specimen ID & $\begin{array}{c}L \\
(\mathrm{~mm})\end{array}$ & $\begin{array}{c}D \\
(\mathrm{~mm})\end{array}$ & $\begin{array}{c}t_{s} \\
(\mathrm{~mm})\end{array}$ & $\begin{array}{c}f_{y} \\
(\mathrm{MPa})\end{array}$ & $\begin{array}{c}f_{c} \\
(\mathrm{MPa})\end{array}$ & $\begin{array}{c}f_{c, d} \\
(\mathrm{MPa})\end{array}$ & $\begin{array}{c}d_{e} \\
(\mathrm{~mm})\end{array}$ & $\begin{array}{c}P_{\text {test }} \\
(\mathrm{kN})\end{array}$ & $\begin{array}{c}P_{F E} \\
(\mathrm{kN})\end{array}$ & $\frac{P_{F E}}{P_{\text {test }}}$ \\
\hline \multirow{9}{*}{ [44] } & M1 & 3327.4 & 169.42 & 5.11 & 308.9 & 45.6 & 38.8 & 47.6 & 621.8 & 604.5 & 0.97 \\
\hline & M2 & 3327.4 & 169.16 & 5.26 & 308.9 & 43.8 & 37.2 & 38.1 & 701.5 & 668.3 & 0.95 \\
\hline & M3 & 3327.4 & 168.91 & 5.66 & 295.0 & 33.4 & 28.4 & 47.6 & 599.8 & 571.9 & 0.95 \\
\hline & M4 & 3327.4 & 168.40 & 6.55 & 298.1 & 30.6 & 26.0 & 47.6 & 624.7 & 611.0 & 0.98 \\
\hline & M5 & 3327.4 & 169.16 & 7.19 & 312.0 & 26.4 & 22.4 & 47.6 & 652.6 & 654.2 & 1.00 \\
\hline & M6 & 3327.4 & 169.16 & 7.29 & 312.0 & 27.3 & 23.2 & 38.1 & 738.3 & 732.2 & 0.99 \\
\hline & M7 & 3302.0 & 168.91 & 8.81 & 322.8 & 27.2 & 23.1 & 47.6 & 757.3 & 771.9 & 1.02 \\
\hline & \multicolumn{10}{|c|}{ Mean (group) } & 0.98 \\
\hline & & & & ndard & viation & roup) & & & & & 0.023 \\
\hline \multirow{17}{*}{ [45] } & SC-0 & 802 & 76.0 & 2.2 & 435.0 & 58.0 & 49.3 & 15.0 & 246.0 & 242.0 & 0.98 \\
\hline & SC-1 & 1032 & 76.0 & 2.2 & 435.0 & 58.0 & 49.3 & 15.0 & 208.0 & 215.6 & 1.04 \\
\hline & SC-2 & 1262 & 76.0 & 2.2 & 435.0 & 58.0 & 49.3 & 15.0 & 184.0 & 193.5 & 1.05 \\
\hline & SC-3 & 1487 & 76.0 & 2.2 & 435.0 & 58.0 & 49.3 & 15.0 & 162.0 & 173.0 & 1.07 \\
\hline & SC-4 & 1717 & 76.0 & 2.2 & 435.0 & 58.0 & 49.3 & 15.0 & 141.0 & 153.7 & 1.09 \\
\hline & SC-5 & 1947 & 76.0 & 2.2 & 435.0 & 58.0 & 49.3 & 15.0 & 121.0 & 135.7 & 1.12 \\
\hline & SC-6 & 2172 & 76.0 & 2.2 & 435.0 & 58.0 & 49.3 & 15.0 & 107.0 & 119.9 & 1.12 \\
\hline & SC-7 & 2402 & 76.0 & 2.2 & 435.0 & 58.0 & 49.3 & 15.0 & 96.0 & 105.5 & 1.10 \\
\hline & SC-9 & 1947 & 101.7 & 2.4 & 410.0 & 58.0 & 49.3 & 10.0 & 361.0 & 360.3 & 1.00 \\
\hline & SC-10 & 1947 & 101.7 & 2.4 & 410.0 & 58.0 & 49.3 & 15.0 & 309.0 & 311.8 & 1.01 \\
\hline & SC-11 & 1947 & 101.7 & 2.4 & 410.0 & 58.0 & 49.3 & 20.0 & 275.0 & 276.4 & 1.01 \\
\hline & SC-12 & 1947 & 101.7 & 2.4 & 410.0 & 58.0 & 49.3 & 25.0 & 240.0 & 250.4 & 1.04 \\
\hline & SC-13 & 1947 & 101.7 & 2.4 & 410.0 & 58.0 & 49.3 & 30.0 & 220.0 & 229.5 & 1.04 \\
\hline & SC-14 & 1947 & 101.7 & 2.4 & 410.0 & 58.0 & 49.3 & 40.0 & 188.0 & 196.0 & 1.04 \\
\hline & SC-15 & 1947 & 101.7 & 2.4 & 410.0 & 58.0 & 49.3 & 50.0 & 158.0 & 169.1 & 1.07 \\
\hline & \multicolumn{10}{|c|}{ Mean (group) } & 1.05 \\
\hline & & & & ndard & viation & roup) & & & & & 0.042 \\
\hline \multirow{24}{*}{ [46] } & S30E210B & 660.0 & 165.0 & 2.82 & 363.3 & 112.7 & 95.8 & 6.8 & 2246.0 & 2296.1 & 1.02 \\
\hline & S30E110B & 660.0 & 165.0 & 2.82 & 363.3 & 112.7 & 95.8 & 15.6 & 1880.0 & 1967.6 & 1.05 \\
\hline & S30E280A & 661.0 & 165.0 & 2.82 & 363.3 & 80.2 & 68.2 & 9.4 & 1904.0 & 1767.2 & 0.93 \\
\hline & S30E180A & 661.0 & 165.0 & 2.82 & 363.3 & 80.2 & 68.2 & 17.9 & 1653.0 & 1541.9 & 0.93 \\
\hline & S30E150B & 661.5 & 165.0 & 2.82 & 363.3 & 48.3 & 41.1 & 17.2 & 1123.0 & 1184.7 & 1.05 \\
\hline & S30E250B & 662.0 & 165.0 & 2.82 & 363.3 & 48.3 & 41.1 & 7.0 & 1525.0 & 1358.9 & 0.89 \\
\hline & S16E110B & 742.0 & 190.0 & 1.52 & 306.1 & 112.7 & 95.8 & 12.9 & 2420.0 & 2386.9 & 0.99 \\
\hline & S20E250A & 742.5 & 190.0 & 1.94 & 256.4 & 41.0 & 34.9 & 8.6 & 1533.0 & 1216.6 & 0.79 \\
\hline & S20E210B & 743.0 & 190.0 & 1.94 & 256.4 & 112.7 & 95.8 & 6.5 & 2683.0 & 2644.4 & 0.99 \\
\hline & S10E250A & 743.5 & 190.0 & 0.86 & 210.7 & 41.0 & 34.9 & 7.4 & 1219.0 & 1009.9 & 0.83 \\
\hline & S12E110B & 743.5 & 190.0 & 1.13 & 185.7 & 112.7 & 95.8 & 17.1 & 1925.0 & 2073.6 & 1.08 \\
\hline & S16E150B & 743.5 & 190.0 & 1.52 & 306.1 & 48.3 & 41.1 & 15.5 & 1260.0 & 1217.6 & 0.97 \\
\hline & S20E280B & 744.0 & 190.0 & 1.94 & 256.4 & 74.7 & 63.5 & 10.0 & 2203.0 & 1806.1 & 0.82 \\
\hline & S10E150A & 744.5 & 190.0 & 0.86 & 210.7 & 41.0 & 34.9 & 13.9 & 1017.0 & 923.2 & 0.91 \\
\hline & S20E180B & 744.5 & 190.0 & 1.94 & 256.4 & 74.7 & 63.5 & 20.8 & 1730.0 & 1542.6 & 0.89 \\
\hline & S12E250A & 745.0 & 190.0 & 1.13 & 185.7 & 41.0 & 34.9 & 8.5 & 1229.0 & 1009.8 & 0.82 \\
\hline & S16E180A & 745.0 & 190.0 & 1.52 & 306.1 & 80.2 & 68.2 & 14.3 & 1925.0 & 1789.1 & 0.93 \\
\hline & S12E150A & 745.5 & 190.0 & 1.13 & 185.7 & 41.0 & 34.9 & 18.9 & 1023.0 & 878.6 & 0.86 \\
\hline & S20E150A & 745.5 & 190.0 & 1.94 & 256.4 & 41.0 & 34.9 & 16.2 & 1284.0 & 1099.3 & 0.86 \\
\hline & S20E110B & 746.0 & 190.0 & 1.94 & 256.4 & 112.7 & 95.8 & 17.0 & 2386.0 & 2259.6 & 0.95 \\
\hline & S10E180B & 746.5 & 190.0 & 0.86 & 210.7 & 74.7 & 63.5 & 17.9 & 1532.0 & 1456.7 & 0.95 \\
\hline & S10E280B & 747.0 & 190.0 & 0.86 & 210.7 & 74.7 & 63.5 & 8.6 & 1910.0 & 1663.2 & 0.87 \\
\hline & \multicolumn{10}{|c|}{ Mean (group) } & 0.93 \\
\hline & & & & ndard & viation & roup) & & & & & 0.079 \\
\hline \multirow{10}{*}{ [47] } & ZC-16 & 2000 & 160.3 & 5.10 & 271.0 & 101.0 & 85.9 & 8.0 & 1697.0 & 1567.7 & 0.92 \\
\hline & ZC-17 & 2000 & 160.1 & 4.97 & 281.0 & 102.0 & 86.7 & 16.0 & 1394.0 & 1363.8 & 0.98 \\
\hline & ZC-18 & 2000 & 159.8 & 5.02 & 280.0 & 101.0 & 85.9 & 24.0 & 1212.0 & 1190.8 & 0.98 \\
\hline & ZC-19 & 2000 & 159.7 & 5.02 & 276.0 & 100.0 & 85.0 & 32.0 & 1091.0 & 1040.5 & 0.95 \\
\hline & ZC-20 & 4000 & 159.7 & 4.96 & 275.0 & 101.0 & 85.9 & 8.0 & 963.0 & 947.0 & 0.98 \\
\hline & ZC-21 & 4000 & 159.8 & 4.96 & 275.0 & 100.0 & 85.0 & 16.0 & 848.0 & 793.8 & 0.94 \\
\hline & ZC-22 & 4000 & 159.8 & 5.10 & 281.0 & 102.0 & 86.7 & 24.0 & 727.0 & 707.8 & 0.97 \\
\hline & ZC-23 & 4000 & 160.1 & 5.12 & 281.0 & 101.0 & 85.9 & 32.0 & 666.0 & 638.2 & 0.96 \\
\hline & \multicolumn{10}{|c|}{ Mean (group) } & 0.96 \\
\hline & \multicolumn{10}{|c|}{ Standard deviation (group) } & 0.021 \\
\hline
\end{tabular}


Table 2(b). Data of the eccentrically loaded circular-sectioned CFST specimens (Part II).

\begin{tabular}{|c|c|c|c|c|c|c|c|c|c|c|c|}
\hline Ref. & Specimen ID & $\begin{array}{c}L \\
(\mathrm{~mm})\end{array}$ & $\begin{array}{c}D \\
(\mathrm{~mm})\end{array}$ & $\begin{array}{c}t_{s} \\
(\mathrm{~mm})\end{array}$ & $\begin{array}{c}f_{y} \\
(\mathrm{MPa})\end{array}$ & $\begin{array}{c}f_{c} \\
(\mathrm{MPa})\end{array}$ & $\begin{array}{c}f_{c, d} \\
(\mathrm{MPa})\end{array}$ & $\begin{array}{c}d_{e} \\
(\mathrm{~mm})\end{array}$ & $\begin{array}{l}P_{\text {test }} \\
(\mathrm{kN})\end{array}$ & $\begin{array}{c}P_{F E} \\
(\mathrm{kN})\end{array}$ & $\frac{P_{F E}}{P_{\text {test }}}$ \\
\hline \multirow{10}{*}{ [48] } & NVC-80-1 & 1310 & 139.6 & 4.0 & 374.0 & 62.0 & 52.7 & 25.0 & 756.9 & 844.4 & 1.12 \\
\hline & NVC-80-2 & 1230 & 139.6 & 4.0 & 374.0 & 62.0 & 52.7 & 25.0 & 874.7 & 862.3 & 0.99 \\
\hline & NVC-200-1 & 2125 & 139.6 & 4.0 & 374.0 & 62.0 & 52.7 & 25.0 & 608.2 & 678.9 & 1.12 \\
\hline & NVC-200-2 & 2135 & 139.6 & 4.0 & 374.0 & 62.0 & 52.7 & 25.0 & 605.7 & 678.9 & 1.12 \\
\hline & NVC-300-1 & 3270 & 139.6 & 4.0 & 374.0 & 62.0 & 52.7 & 25.0 & 555.9 & 499.9 & 0.90 \\
\hline & NVC-300-2 & 3270 & 139.6 & 4.0 & 374.0 & 62.0 & 52.7 & 25.0 & 484.1 & 499.9 & 1.03 \\
\hline & NVC-440-1 & 4670 & 139.6 & 4.0 & 374.0 & 62.0 & 52.7 & 25.0 & 336.2 & 330.7 & 0.98 \\
\hline & NVC-440-2 & 4670 & 139.6 & 4.0 & 374.0 & 62.0 & 52.7 & 25.0 & 333.0 & 330.7 & 0.99 \\
\hline & \multicolumn{10}{|c|}{ Mean (group) } & 1.03 \\
\hline & \multicolumn{10}{|c|}{ Standard deviation (group) } & 0.075 \\
\hline \multirow{34}{*}{ [49] } & C100-3-2-30-20-1 & 2135 & 100.0 & 3.0 & 322.0 & 32.7 & 27.8 & 20.0 & 181.6 & 215.7 & 1.19 \\
\hline & C100-3-2-30-50-1 & 2135 & 100.0 & 3.0 & 322.0 & 34.5 & 29.3 & 50.0 & 117.5 & 139.8 & 1.19 \\
\hline & C100-3-2-70-20-1 & 2135 & 100.0 & 3.0 & 322.0 & 65.8 & 55.9 & 20.0 & 248.6 & 261.3 & 1.05 \\
\hline & C100-3-2-70-50-1 & 2135 & 100.0 & 3.0 & 322.0 & 71.6 & 60.9 & 50.0 & 151.6 & 161.8 & 1.07 \\
\hline & C100-3-2-90-20-1 & 2135 & 100.0 & 3.0 & 322.0 & 95.6 & 81.3 & 20.0 & 271.0 & 292.2 & 1.08 \\
\hline & C100-3-2-90-50-1 & 2135 & 100.0 & 3.0 & 322.0 & 93.0 & 79.1 & 50.0 & 154.2 & 169.5 & 1.10 \\
\hline & C100-3-3-30-20-1 & 3135 & 100.0 & 3.0 & 322.0 & 39.4 & 33.5 & 20.0 & 140.3 & 162.3 & 1.16 \\
\hline & C100-3-3-30-50-1 & 3135 & 100.0 & 3.0 & 322.0 & 36.7 & 31.2 & 50.0 & 93.8 & 108.4 & 1.16 \\
\hline & C100-3-3-70-20-1 & 3135 & 100.0 & 3.0 & 322.0 & 71.7 & 60.9 & 20.0 & 159.6 & 180.7 & 1.13 \\
\hline & C100-3-3-70-50-1 & 3135 & 100.0 & 3.0 & 322.0 & 79.6 & 67.7 & 50.0 & 102.8 & 121.1 & 1.18 \\
\hline & C100-3-3-90-20-1 & 3135 & 100.0 & 3.0 & 322.0 & 94.6 & 80.4 & 20.0 & 160.3 & 189.3 & 1.18 \\
\hline & C100-3-3-90-50-1 & 3135 & 100.0 & 3.0 & 322.0 & 90.4 & 76.8 & 50.0 & 106.8 & 122.6 & 1.15 \\
\hline & C100-5-2-30-20-1 & 2135 & 100.0 & 5.0 & 322.0 & 35.4 & 30.1 & 20.0 & 270.0 & 302.7 & 1.12 \\
\hline & C100-5-2-30-50-1 & 2135 & 100.0 & 5.0 & 322.0 & 30.5 & 25.9 & 50.0 & 161.3 & 192.0 & 1.19 \\
\hline & C100-5-2-70-20-1 & 2135 & 100.0 & 5.0 & 322.0 & 70.2 & 59.7 & 20.0 & 313.6 & 345.2 & 1.10 \\
\hline & C100-5-2-70-50-1 & 2135 & 100.0 & 5.0 & 322.0 & 61.0 & 51.9 & 50.0 & 183.8 & 214.9 & 1.17 \\
\hline & C100-5-2-90-20-1 & 2135 & 101.6 & 5.0 & 320.0 & 95.4 & 81.1 & 20.0 & 330.4 & 385.0 & 1.17 \\
\hline & C100-5-2-90-50-1 & 2135 & 101.6 & 5.0 & 320.0 & 81.7 & 69.4 & 50.0 & 213.5 & 234.6 & 1.10 \\
\hline & C100-5-3-30-20-1 & 3135 & 101.6 & 5.0 & 320.0 & 38.7 & 32.9 & 20.0 & 212.5 & 233.9 & 1.10 \\
\hline & C100-5-3-30-50-1 & 3135 & 101.6 & 5.0 & 320.0 & 39.6 & 33.7 & 50.0 & 144.8 & 160.4 & 1.11 \\
\hline & C100-5-3-70-20-1 & 3135 & 101.6 & 5.0 & 320.0 & 71.9 & 61.1 & 20.0 & 231.4 & 254.1 & 1.10 \\
\hline & C100-5-3-70-50-1 & 3135 & 101.6 & 5.0 & 320.0 & 72.5 & 61.6 & 50.0 & 153.2 & 173.4 & 1.13 \\
\hline & C100-5-3-90-20-1 & 3135 & 101.6 & 5.0 & 320.0 & 86.4 & 73.4 & 20.0 & 246.8 & 260.3 & 1.05 \\
\hline & C100-5-3-90-50-1 & 3135 & 101.6 & 5.0 & 320.0 & 96.7 & 82.2 & 50.0 & 165.0 & 179.3 & 1.09 \\
\hline & C125-5-3-90-20-1 & 3135 & 125.0 & 5.0 & 322.0 & 88.0 & 74.8 & 20.0 & 474.2 & 477.9 & 1.01 \\
\hline & C125-5-3-90-50-1 & 3135 & 125.0 & 5.0 & 322.0 & 97.0 & 82.5 & 50.0 & 317.9 & 324.5 & 1.02 \\
\hline & C125-5-3-90-20-2 & 3135 & 125.0 & 5.0 & 322.0 & 107.3 & 91.2 & 20.0 & 489.5 & 497.2 & 1.02 \\
\hline & C125-5-3-90-50-2 & 3135 & 125.0 & 5.0 & 322.0 & 97.9 & 83.2 & 50.0 & 323.0 & 324.9 & 1.01 \\
\hline & C160-6-3-90-20-1 & 3135 & 160.1 & 5.7 & 322.0 & 87.4 & 74.3 & 20.0 & 1012.5 & 1010.5 & 1.00 \\
\hline & C160-6-3-70-50-1 & 3135 & 160.1 & 5.7 & 322.0 & 74.8 & 63.6 & 50.0 & 642.2 & 657.6 & 1.02 \\
\hline & C160-6-3-90-20-2 & 3135 & 160.1 & 5.7 & 322.0 & 83.1 & 70.6 & 20.0 & 1011.5 & 995.3 & 0.98 \\
\hline & C160-6-3-90-50-1 & 3135 & 160.1 & 5.7 & 322.0 & 98.5 & 83.7 & 50.0 & 686.2 & 706.2 & 1.03 \\
\hline & & & & $\mathrm{Me}$ & (group & & & & & & 1.10 \\
\hline & & & & indard & viation & roup) & & & & & 0.063 \\
\hline \multirow{5}{*}[50]{} & N3-0-E & 820 & 219.0 & 3.0 & 313.0 & 51.8 & 44.0 & 50.0 & 1457.0 & 1417.0 & 0.97 \\
\hline & N4-0-E & 820 & 219.0 & 4.0 & 313.0 & 51.8 & 44.0 & 50.0 & 1634.0 & 1589.7 & 0.97 \\
\hline & N5-0-E & 820 & 219.0 & 5.0 & 313.0 & 51.8 & 44.0 & 50.0 & 1874.0 & 1740.6 & 0.93 \\
\hline & \multicolumn{10}{|c|}{ Mean (group) } & 0.96 \\
\hline & \multicolumn{10}{|c|}{ Standard deviation (group) } & 0.021 \\
\hline
\end{tabular}


Table 3. Convergence study on FE analysis of ZC-16

\begin{tabular}{|c|c|c|c|c|}
\hline $\begin{array}{c}\text { Nominal } \\
\text { element size } \\
(\mathrm{mm})\end{array}$ & $\begin{array}{c}\text { Number of } \\
\text { elements }\end{array}$ & $\begin{array}{c}\text { Predicted } \\
\text { max. load } \\
(\mathrm{kN})\end{array}$ & $\begin{array}{c}\text { Error in } \\
\text { predicted } \\
\text { max. load (\%) }\end{array}$ & $\begin{array}{c}\text { Computer } \\
\text { time up to 500 } \\
\text { displacement } \\
\text { steps (s) }\end{array}$ \\
\hline 5 & 355 & 1606.2 & $3.3 \%$ & 213 \\
\hline 4 & 523 & 1597.0 & $2.7 \%$ & 327 \\
\hline 3 & 835 & 1585.1 & $1.9 \%$ & 540 \\
\hline 2 & 1843 & 1567.7 & $0.8 \%$ & 1352 \\
\hline 1.5 & 3130 & 1558.5 & $0.2 \%$ & 2412 \\
\hline 1 & 6883 & 1554.9 & - & 6847 \\
\hline
\end{tabular}

Basic configuration of computer used for analysis:

CPU: Intel Core i7-4790K CPU @ 4.00 GHz; RAM: 16 GB of DDR3-1600. 